\title{
Actin Polymerization-Dependent Increase in Synaptic Arc/Arg3.1 Expression in the Amygdala Is Crucial for the Expression of Aversive Memory Associated with Drug Withdrawal
}

\author{
Yao Liu, ${ }^{1 \star}$ Qi-Xin Zhou, ${ }^{2 *}$ Yuan-Yuan Hou, ${ }^{1 *}$ Bin Lu, ${ }^{1}$ Chuan Yu, ${ }^{1}$ Jie Chen, ${ }^{1}$ Qing-Lan Ling, ${ }^{1}$ Jun Cao, ${ }^{2}$ Zhi-Qiang Chi, ${ }^{1}$ \\ Lin $\mathrm{Xu}^{2}{ }^{2}$ and Jing-Gen Liu ${ }^{1}$ \\ ${ }^{1}$ State Key Laboratory of Drug Research, Shanghai Institute of Materia Medica, Shanghai Institutes for Biological Sciences, Chinese Academy of Sciences, \\ Shanghai 201203, China, and 2Laboratory of Learning and Memory, Kunming Institute of Zoology, The Chinese Academy of Sciences, Kunming 65022, \\ China
}

Aversive memories associated with drug withdrawal may contribute to persistent drug seeking. Molecular mechanisms that are critical for aversive memory formation have yet to be elucidated. Recently, we showed in a rat conditioned place aversion (CPA) model that synaptic actin polymerization in the amygdala were required for aversive memory information. Here, we demonstrated that actin polymerization within the amygdala triggered transportation of activity-regulated cytoskeletal-associated protein (Arc/Arg3.1) into amygdalar synapses. Increased synaptic Arc/Arg3.1 expression contributed to aversive memory formation by regulating synaptic AMPA receptor (AMPAR) endocytosis, as in vivo knockdown of amygdalar Arc/Arg3.1 with Arc/Arg3.1-shRNA prevented both AMPAR endocytosis and CPA formation. We also demonstrated that conditioned morphine withdrawal led to induction of LTD in the amygdala through AMPAR endocytosis. We further demonstrated that Arc/Arg3.1-regulated AMPAR endocytosis was GluR2 dependent, as intraamygdala injection of Tat-GluR2 $2_{3 Y}$, a GluR2-derived peptide that has been shown to specifically block regulated, but not constitutive, AMPAR endocytosis, prevented AMPAR endocytosis, LTD induction, and aversive memory formation. Therefore, this study extends previous studies on the role of actin polymerization in synaptic plasticity and memory formation by revealing the critical molecular events involved in aversive memory formation as well as LTD induction, and by showing that Arc/Arg3.1 is a crucial mediator for actin polymerization functions, and, thus, underscores the unknown details of how actin polymerization mediates synaptic plasticity and memory.

\section{Introduction}

Opiate addiction is the chronic relapsing disorder characterized by compulsive drug taking (Kenny, 2007). The maintenance of compulsive use of the drugs is substantially motivated by the negative reinforcing effects of drug withdrawal (Wikler and Pescor, 1967; Hutcheson et al., 2001). Conditioned place aversion (CPA), a model of Pavlovian associative learning, is a sensitive animal model for measurement of the negative affective compo-

\footnotetext{
Received Feb. 22, 2012; revised June 21, 2012; accepted July 3, 2012.

Author contributions: Y.L., Q.-X.Z., Y.-Y.H., B.L., Z.-Q.C., L.X., and J.-G.L. designed research;Y.L., Q.-X.Z., Y.-Y.H., B.L., C.Y., J. Chen, Q.-L.L., and J. Cao performed research; Y.L., Q.-X.Z., Y.-Y.H., B.L., L.X., and J.-G.L. contributed unpublished reagents/analytic tools; Y.L., Q.-X.Z., and Y.-Y.H. analyzed data; Y.L., L.X., and J.-G.L. wrote the paper.

This research was supported by grants from the National Basic Research Program, from the Ministry of Science and Technology of China [2009CB522005 (J.-G.L.), 2009 CB522006 (J.C.), and 2009CB941302 to (L.X.)], and the Foundation of National Natural Science of China 81130087 (J.-G.L.), 81001424 (Y.-Y. H.), 31100775 (Q.-X.Z.), U1032605 (L.X.), and U1132602 (J.C.)], and the grant from Chinese Academy of Sciences [KSCX2-YW-R-253 (J.-G.L.)]. We thank Dr. Xia Zhang for valuable experimental support.

*Y.L., Q.-X.Z., and Y.-Y.H. contributed equally to this work.

Correspondence should be addressed to either Jing-Gen Liu or Lin $\mathrm{Xu}$ at the above addresses. E-mail: jgliu@mail.shcnc.ac.cn; or lxu@vip.163.com.

DOI:10.1523/JNEUROSCI.0871-12.2012

Copyright $\odot 2012$ the authors $\quad 0270-6474 / 12 / 3212005-13 \$ 15.00 / 0$
}

nents of morphine withdrawal in dependent animals (Mucha et al., 1982). The amygdala is a crucial component of the neuronal circuitry mediating associative learning and also is a critical mediator of aversively emotional learning (LeDoux, 2000). Using a CPA model, we revealed recently that actin polymerization in the amygdala underlies the formation of aversive memories associated with morphine withdrawal (Hou et al., 2009). However, the molecular mechanisms underlying such an effect of actin polymerization remain to be established.

Cytoskeletal actin is the major structural component of the dendritic spine (Halpain, 2000), and its dynamics between G-actin and F-actin, namely actin rearrangements, have been shown to play a role in synaptic and behavioral plasticity (Toda et al., 2006; Rex et al., 2010). The cytoskeletal actin could contribute to synaptic plasticity by several possibilities (Halpain, 2000; Schafer, 2002). One potential possibility may be the regulation of AMPA receptor (AMPAR) trafficking, as several lines of evidence support a role for actin polymerization in clathrin-mediated endocytosis (Schafer, 2002; Yarar et al., 2005). Regulation of AMPAR endocytosis and recycling is a principal mechanism for activity-dependent synaptic plasticity (e.g., LTP, LTD, and ho- 
meostatic plasticity) (Bredt and Nicoll, 2003; Anggono and Huganir, 2012). AMPA receptor-mediated glutamate transmission and AMPAR trafficking in the nucleus accumbens and prefrontal cortex also play a central role in some behavioral adaptations (e.g., behavioral sensitization, drug- or cue-induced relapse to drug-seeking) resulting from addictive drug exposure (Brebner et al., 2005; Van den Oever et al., 2008; Kalivas, 2009). Although there is growing evidence that actin polymerization plays a critical role in clathrin-mediated endocytosis in many cell types, little is known about the role of actin polymerization within synapses in activity-dependent AMPAR endocytosis and the mechanisms underlying actin polymerization regulation of AMPAR endocytosis.

In addition to dependence on actin polymerization in the synapses, synaptic plasticity and memory formation also rely on gene and protein synthesis at synapses (Steward and Worley, 2002; Kelleher et al., 2004). The activity-regulated cytoskeletalassociated gene Arc, also known as Arg3.1, is necessary for the stabilization of the synaptic plasticity and for the some forms of long-term memory (Guzowski et al., 2000; Plath et al., 2006). Arc/Arg3.1 has been shown to interact with endophilin2/3 and dynamin to modulate AMPAR endocytosis, thus allowing Arc/ Arg3.1 to influence synaptic strength and excitability as well as synaptic homeostasis (Chowdhury et al., 2006; Rial Verde et al., 2006; Shepherd et al., 2006). Although these recent in vitro studies have demonstrated a role of Arc/Arg3.1 in mediation of AMPAR endocytosis, few studies have examined whether a similar effect of Arc/Arg3.1 on AMPAR endocytosis also occurs in vivo in response to stimulus known to cause synaptic plasticity and memories, and whether this regulatory process plays an essential role in synaptic plasticity and memory formation. In the present study, using the CPA model, we tested the hypothesis that actin polymerization and Arc/Arg3.1 expression within synapses may have a causal relation to function, and their interaction may be required for the regulation of postsynaptic AMPAR endocytosis, thereby contributing to the synaptic plasticity and memory formation.

\section{Materials and Methods}

\section{Animals}

Sprague Dawley male rats weighting 220-300 g were obtained from the Laboratory Animal Center, Chinese Academy of Sciences (Shanghai, China). Rats were housed 2-3 per cage and maintained on a $12 \mathrm{~h} \mathrm{light/}$ dark cycle with access to food and water ad libitum. All experimental procedures were in strict accordance with the National Institutes of Health Guide for the Care and Use of Laboratory Animals.

\section{Drugs and antibodies}

Morphine hydrochloride was purchased from Qinghai Pharmaceutical General Factory. Naloxone hydrochloride, D-AP5, and CNQX were supplied by Sigma Aldrich. Latrunculin A and Y27632 were obtained from Calbiochem. Tat-GluR2 $2_{3 \mathrm{Y}}$ and Tat-GluR2 $2_{38}$ were obtained from AnaSpec. The antibodies of anti-actin were purchased from Sigma-Aldrich and diluted 1:5000, and the antibodies of anti-Arc were obtained from Santa Cruz Biotechnology and diluted 1:1000 for Western blot analysis. The antibodies of anti-GluR1 and anti-GluR2 were purchased from Millipore and diluted 1:5000 for Western blot analysis.

\section{Conditioned place aversion}

The CPA apparatus (Anilab Software and Instruments) was divided into two equal-sized compartments [55 cm (length) $\times 30 \mathrm{~cm}$ (width) $\times 30$ $\mathrm{cm}($ height) ] separated by a removable board $(10 \times 10 \mathrm{~cm})$, which allowed rats free access to each compartment. Two compartments were distinguished by visual and tactile cues: the one was a blank wall with a smooth floor, whereas the other was a white wall with a textured floor. These distinctive tactile and visual stimuli served as the conditioning cues. Conditioned morphine withdrawal procedure has been described previously (Hou et al., 2009). Briefly, animals experienced three phases: preconditioning, conditioning, and testing. In the preconditioning phase, rats were allowed to freely explore the entire apparatus for $15 \mathrm{~min}$. Time spent in each compartment was recorded, and those showing a strong unconditioned aversion (one compartment $>720$ s) for either compartment were eliminated from the study. Conditioning took place over the next $2 \mathrm{~d}$. On the first day, the rats were injected with saline (1 $\mathrm{ml} / \mathrm{kg}$, s.c.) and then returned to home cages. Four hours later, they were given saline again and then confined to either compartment in a counterbalanced manner for $30 \mathrm{~min}$. On the second day, the rats were injected with either morphine $(10 \mathrm{mg} / \mathrm{kg}$, s.c.) or saline $(1 \mathrm{ml} / \mathrm{kg}$, s.c. $)$ and then returned to their home cages. Four hours later, they were injected with either naloxone $(0.3 \mathrm{mg} / \mathrm{kg}$, s.c. $)$ or saline and then confined to the compartment opposite to the first day for $30 \mathrm{~min}$. This compartment will be referred to as the "drug treatment-paired compartment." Testing phase took place $24 \mathrm{~h}$ after the conditioning trial, and all rats were allowed to freely explore the entire apparatus for $15 \mathrm{~min}$; the amount of time spent in each compartment was recorded. The CPA score represents the time in the drug treatment-paired compartment during the testing phase minus that during the preconditioning phase. For Western blotting analysis, rats were perfused immediately on the second day of CPA conditioning.

\section{Subcellular fractionation}

Rats were anesthetized and killed by decapitation. Coronal brain sections ( $1 \mathrm{~mm}$ thick) were obtained using a rat brain slicer (Braintree Scientific). Both sides of the amygdala were punched from brain slices using a bluntend, 17-gauge syringe needle (1 mm inner diameter). The tissue of amygdala punched included most of the central and lateral, basolateral nuclei of the amygdala. In all subsequent procedures, the tissues were maintained at $4^{\circ} \mathrm{C}$. A crude synaptosomal fraction was made according to the procedure of Whittaker and Gray (1962). Briefly, the tissue was homogenized with 10 strokes with a Teflon pestle in 10 volumes of $0.32 \mathrm{M}$ sucrose. The homogenate was centrifuged at $1000 \times g$ for $10 \mathrm{~min}$, and the pellet was discarded. The supernatant was then centrifuged at $17,000 \times g$ for $30 \mathrm{~min}$. The resultant $\mathrm{P} 2$ pellet was washed in an equal volume of 0.32 $\mathrm{M}$ sucrose and recentrifuged at $17,000 \times g$ for another $30 \mathrm{~min}$. The pellet was used as intact synaptosomes.

Subcellular fractionation and actin analysis of the dissected brain tissue was performed as described previously (Hou et al., 2009). Briefly, the crude synaptosome fraction was dissolved hypo-osmotically and centrifuged at $25,000 \times g$ for $25 \mathrm{~min}$ to precipitate a synaptosomal membrane fraction (LP1). To separate F-actin and G-actin, LP1 was lysed in buffer A (1\% Triton X-100, 20 mм HEPES, 100 mм NaCl, 2 mм EDTA, 5 mм NaF, $1 \mathrm{~mm} \mathrm{Na}_{3} \mathrm{VO}_{4}, 1 \mathrm{~mm}$ aprotinin, $1 \mathrm{~mm}$ leupeptin, $1 \mathrm{~mm}$ PMSF, pH7.2) for $1 \mathrm{~h}$ and centrifuged at $10,000 \times g$ for $20 \mathrm{~min}$. Pellets were dissolved in buffer B (15 mm HEPES, 0.15 mm NaCl, 1\% SDS, 10 mm EDTA, 1 mm DTT, $5 \mathrm{~mm} \mathrm{NaF}, 1 \mathrm{~mm} \mathrm{Na} \mathrm{VO}_{4}, 1 \mathrm{~mm}$ aprotinin, $1 \mathrm{~mm}$ leupeptin, $1 \mathrm{~mm}$ PMSF, pH7.5) for $1 \mathrm{~h}$ and centrifuged at $10,000 \times g$ for $20 \mathrm{~min}$. The G-actin fraction (the first supernatant) and the F-actin fractin (the second supernatant) were collected.

\section{Immunoblotting of Arc/Arg3.1}

Equal amounts of protein were electrophoresed on 12\% SDSpolyacrylamide gels and transferred to nitrocellulose membranes. Arc was detected using a monoclonal mouse anti-arc serum (sc-17839, Santa Cruz Biotechnology) at a 1:1000 dilution in TBS containing 5\% nonfat dry milk and $0.05 \%$ Tween-20. After incubation with HRP-conjugated goat anti-mouse IgG (Santa Cruz Biotechnology) at a 1:2000 dilution, bands were developed with a chemiluminescent substrate (RPN2132, GE Healthcare). The immunopositive signals were quantified by Quantity One software (Bio-Rad).

\section{Intracerebral microinjection}

Rats were anesthetized using sodium pentobarbital (50 mg/kg, i.p.), treated with atropine sulfate $(0.2 \mathrm{mg} / \mathrm{kg}$, i.p.), and then placed in a stereotaxic apparatus (Narishige) with the incisor bar set at $3.3 \mathrm{~mm}$. Rats were implanted bilaterally with guide cannulae (26 gauge) in the amygdala (AP, $-2.8 \mathrm{~mm}$; ML, $\pm 4.5 \mathrm{~mm}$; DV, $-6.0 \mathrm{~mm}$ ). Bilateral microinfusions were made through 31 gauge injection cannulae $(2.0 \mathrm{~mm}$ 
beyond the tip of guide cannulae), which was connected to a $10 \mu \mathrm{lmi}$ crosyringe mounted in the microinfusion pump (Harvard Apparatus) for no less than $2 \mathrm{~min}$ and given an additional $2 \mathrm{~min}$ for drug diffusion. Latrunculin A was dissolved in DMSO $(25 \mu \mathrm{g} / \mu \mathrm{l}$ stock solution $)$ and diluted in PBS to a final concentration of $0.5 \mu \mathrm{g} / \mu \mathrm{l}$. Latrunculin A was bilaterally microinjected into the amygdala $10 \mathrm{~min}$ before pairing. Y27632 and D-AP5 were dissolved in PBS before use and were bilaterally microinjected into the amygdala 30 and $10 \mathrm{~min}$ before pairing, respectively. CNQX was dissolved in DMSO $(50 \mu \mathrm{g} / \mu \mathrm{l}$ stock solution) and diluted in PBS to a final concentration of $60 \mathrm{nmol} / \mu \mathrm{l}$, and was bilaterally microinjected into the amygdala $10 \mathrm{~min}$ before pairing. Tat-GluR $2_{3 \mathrm{Y}}$ and Tat-GluR2 ${ }_{3 S}$ were dissolved in PBS to a concentration of $30 \mathrm{pmol} / \mu \mathrm{l}$, and were bilaterally microinjected into the amygdala $60 \mathrm{~min}$ before pairing. The doses of latrunculin A, Y27632, D-AP5, CNQX, Tat-GluR2 3 , and Tat-GluR2 $2_{3 S}$ were chosen based on pilot experiments and previous studies.

\section{Histology}

After behavior testing, rats were deeply anesthetized with sodium pentobarbital and perfused transcardially with $0.9 \%$ saline followed by $4 \%$ paraformaldehyde in PBS. The brains were removed and stored in a $30 \%$ sucrose/PBS solution for $2-3 \mathrm{~d}$. Coronal sections ( $30 \mu \mathrm{m}$ thick) were cut on a cryostat (Leica), stained with cresyl violet, and then examined by light microscopy to determine injection sites.

\section{Lentivirus construction and infection}

Production and testing of recombinant lentiviral vectors. The lentiviral plasmid pSicoR was purchased from Addgene, and oligos coding for the various shRNAs were annealed and cloned into $\mathrm{HpaI}$-XhoI-digested pSicoR vectors. The following target shRNA regions were chosen: ARC, GCTGATGGCTACGACTACA; negative control, TTCTCCGAACGTGTCACGT. Lentiviruses were generated essentially as described in the following. Briefly, $5 \mu \mathrm{g}$ of lentiviral vector and $2.5 \mu \mathrm{g}$ of each packaging vector were cotransfected in 293T cells by using the FuGENE 6 reagent (Roche Diagnostics). Supernatants were collected 36-48 h after transfection, filtered through a $0.4 \mu \mathrm{m}$ filter. High-titer stocks were prepared by an initial ultracentrifugation for $1 \mathrm{~h}$ at 23,000 rpm (SW-28 rotor; Beckman Coulter) and a secondary tabletop centrifugation at 13,000 $\times g$ for $30 \mathrm{~min}$. Viral pellet was resuspended in 1\% BSA/PBS and stored at $-80^{\circ} \mathrm{C}$. Viral titers were determined by infection of HEK293T cells, and GFP-positive cells were visualized by fluorescent microscopy. After concentration, viral titers were $5 \times 10^{8}-2 \times 10^{9}$ transducing units $(\mathrm{TU}) / \mathrm{ml}$. The high-titer lentiviral stocks were then used directly to infect cultured neurons or microinject into the rat brains.

Stereotaxic vector injections into rat amygdala. Rats were anesthetized using sodium pentobarbital (50 mg/kg, i.p.), treated with atropine sulfate $(0.2 \mathrm{mg} / \mathrm{kg}$, i.p.), and then placed in a stereotaxic apparatus (Narishige) with the incisor bar set at $3.3 \mathrm{~mm}$. Rats were implanted bilaterally with guide cannulae (26 gauge) in the amygdala (AP, $-2.8 \mathrm{~mm}$; ML, \pm 4.5 $\mathrm{mm}$; DV , $-6.0 \mathrm{~mm})$. Lentivirus $\left(5 \times 10^{8}-1 \times 10^{9} \mathrm{TU} / \mathrm{ml}\right)$ was stereotaxically injected into the amygdala $(3 \mu \mathrm{l} / \mathrm{site})$ over $5 \mathrm{~min}$ using a 31 gauge injection cannula ( $2.0 \mathrm{~mm}$ beyond the tip of guide cannula), which was connected to a $10 \mu \mathrm{l}$ microsyringe mounted in the microinfusion pump (Harvard Apparatus). The needle was retained in place for another $5 \mathrm{~min}$ before being withdrawn at $1 \mathrm{~mm} / \mathrm{min}$. At $2-3$ weeks post-injection, anesthetized rats were perfused transcardially with $0.9 \%$ saline followed by $4 \%$ paraformaldehyde in PBS. The brains were removed and postfixed in $4 \%$ paraformaldehyde for $24 \mathrm{~h}$ and then cryoprotected in $30 \%$ sucrose. Frozen coronal sections $(30 \mu \mathrm{m})$ were made through the amygdala using a cryostat (Leica); the fluorescence was examined by fluorescence microscopy (Olympus).

\section{Surface receptor cross-linking with $B S^{3}$}

Surface and intracellular GluR1- and GluR2-containg AMPAR levels were determined with a protein cross-linking assay as previously described (Boudreau and Wolf, 2005), with minor modifications. Briefly, rat brain tissue was incubated with protein cross-linking reagent bis (sulfosuccinimidyl) suberate ( $\mathrm{BS}^{3}$; Pierce Biotechnology) to determine $\mathrm{S}$ (surface) and I (intracellular) levels of receptor subunit proteins. After the last pairing of naloxone or saline, rats were decapitated. Brains were rapidly removed, and coronal brain sections (500 $\mu \mathrm{m}$ thick) containing the amygdala were obtained using a rat brain slicer (Braintree Scientific). Slices were then added to $2 \mathrm{ml}$ eppendorf tubes containing $1 \mathrm{ml}$ of artificial CSF (ACSF) spiked with $2 \mathrm{~mm} \mathrm{BS}^{3}$. The ACSF contained the following (in mM): $\mathrm{NaCl} 120, \mathrm{KCl} 2.5, \mathrm{NaHCO}_{3} 26, \mathrm{NaH}_{2} \mathrm{PO}_{4} 1.25, \mathrm{CaCl}_{2} 2$, $\mathrm{MgSO}_{4} 2$, and D-glucose 10 , and was bubbled with the gas mixture of $95 \%$ $\mathrm{O}_{2}$ and $5 \% \mathrm{CO}_{2}$ for at least $1 \mathrm{~h}$. Incubation with gentle agitation proceeded for $30 \mathrm{~min}$ at $4^{\circ} \mathrm{C}$. Cross-linking was terminated by quenching the reaction with $100 \mathrm{~mm}$ glycine $\left(10 \mathrm{~min}, 4^{\circ} \mathrm{C}\right)$. The slices were pelleted for $2 \mathrm{~min}$ at 14,000 rpm, and the supernatant was discarded. Pellets were resuspended in ice-cold lysis buffer containing protease and phosphatase inhibitors and homogenized rapidly by sonicating, samples were centrifuged at 14,000 rpm for $2 \mathrm{~min}$, and the supernatant fraction were collected for Western blotting. Total protein concentration of lysates was determined by The Precision Red Advanced Protein Assay (Cat. \# ADV02, Cytoskeleton). Samples were aliquoted and stored at $-80^{\circ} \mathrm{C}$ for future analysis.

\section{Electrophysiology}

After different training according to experimental design, the rats were deeply anesthetized with diethyl ether and the brain was rapidly removed and immersed in ice-cold ACSF continuously bubbled with the gas mixture of $95 \% \mathrm{O}_{2}$ and $5 \% \mathrm{CO}_{2}$. Amygdalar slices were cut coronally and then transferred to an incubation chamber containing ACSF heated to $36 \pm 1^{\circ} \mathrm{C}$ for $20 \mathrm{~min}$ recovery and then maintained at room temperature $\left(22-25^{\circ} \mathrm{C}\right)$. Slices were placed in a recording chamber and perfused by oxygen saturated ACSF with a flow rate of $4-5 \mathrm{ml} / \mathrm{min}$. Recordings were made just below the site of termination of thalamic fibers terminating in the lateral amygdala by a glass recording electrode filled with ACSF (4-6 $\mathrm{M} \Omega$ ). The stimulation was adjusted for each slice to produce reliable field potential that was approximately $50 \%$ of maximal response. LTD was elicited by low-frequency stimuli (LFS, $1 \mathrm{~Hz}, 900$ pulses) after baseline was stably recorded for at least $20 \mathrm{~min}$ at a frequency of $0.033 \mathrm{~Hz}$.

\section{Data analysis}

The data were analyzed with two-tailed Student's $t$ tests, or one-way ANOVA, and then followed by Newman-Keuls post hoc tests when appropriate. Differences with $p<0.05$ were considered statistically significant. The results are presented as mean \pm SEM.

\section{Results}

Actin polymerization occurred in the amygdala through RhoA-ROCK signaling and depended on NMDA receptor activation after conditioned morphine withdrawal

Our previous study reveals that conditioned morphine withdrawal (CMW) induces synaptic actin polymerization in the amygdala of rats, characterized by a significant elevation of polymerized F-actin and a decrease of monomeric G-actin, which contributes to CPA formation (Hou et al., 2009). To investigate mechanisms by which actin polymerization modulates CPA formation, in this study, we first determined molecular events involved in the actin polymerization. Previous studies have demonstrated that actin polymerization in the hippocampus induced by HFS depends on NMDA receptor activation and can be blocked by Rho kinase (ROCK) inhibitors (Fukazawa et al., 2003; Huang et al., 2007). To determine whether actin polymerization in the amygdala induced by CMW also depends on NMDA receptor activation and is mediated by ROCK, we examined the effects of Y27632, a highly selective and potent ROCK inhibitor, and D-AP5, an NMDA-receptor antagonist, on synaptic actin polymerization in the amygdala induced by CMW. Consistent with our previous observations, a significant synaptic actin polymerization in the amygdala was observed in rats $1 \mathrm{~h}$ after CMW (Fig. 1A,B). Bilateral microinjection of either Y27632 $(8.56 \mu \mathrm{g} /$ $0.5 \mu \mathrm{l} /$ side $)$ or D-AP5 ( $4 \mu \mathrm{g} / 0.5 \mu \mathrm{l} /$ side) into the rat amygdala 30 min or 10 min before CMW significantly blocked synaptic actin polymerization induced by CMW (Y27632, $41.51 \pm 11.07 \%$ of 

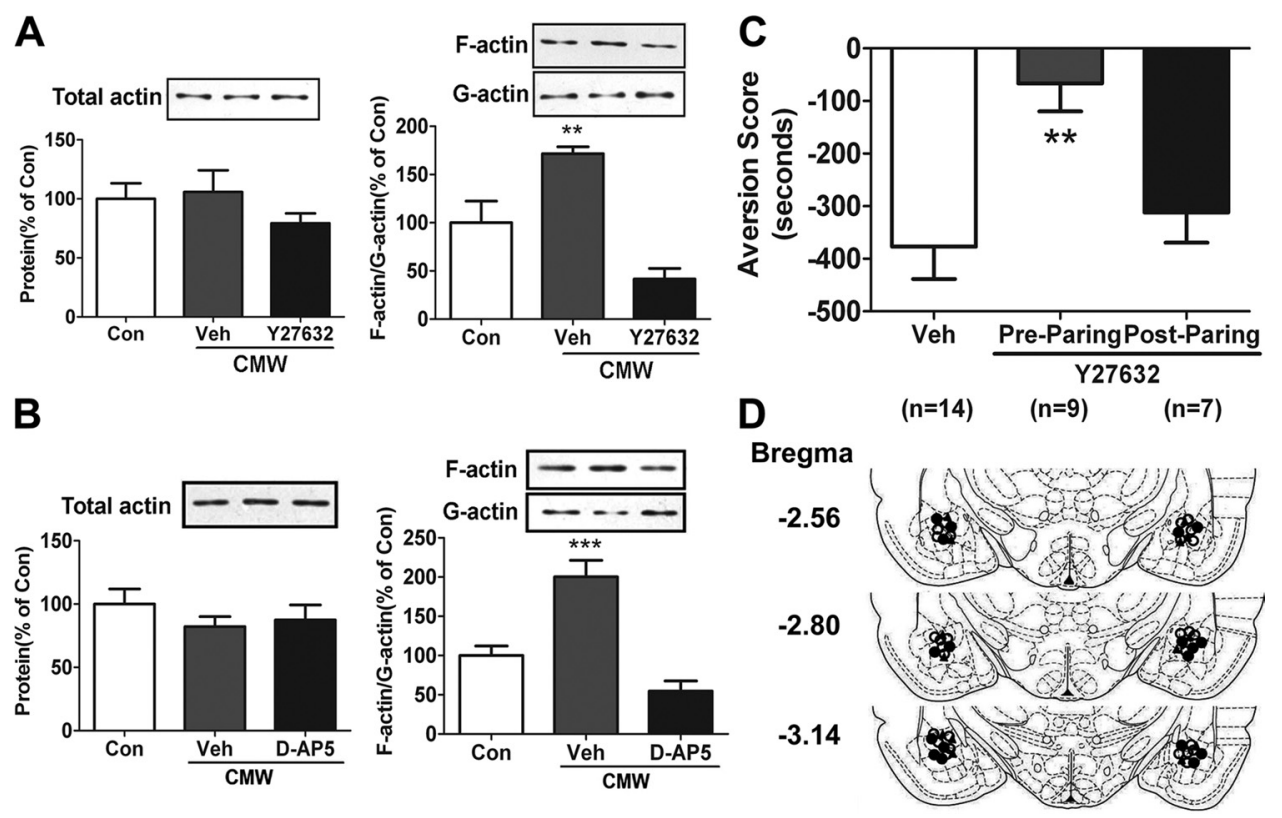

Figure 1. Amygdalar synaptic actin polymerization induced by CMW was involved in the RhoA-ROCK signaling pathway and depended on NMDA receptor activation, and blockade of actin polymerization with Y27632 prevented CPA formation. $A, B$, Effects of ROCK inhibitor Y27632 or NMDA antagonist D-AP5 on the ratio of F-actin to G-actin in the amygdala at $0.5 \mathrm{~h}$ after CMW. $\boldsymbol{C}$, Prepairing but not postpairing intra-amygdala injection of $\mathrm{Y} 27632$ disrupted CPA formation induced by CMW. Error bars represent mean \pm SEM. ${ }^{* *} p<0.01$, ${ }^{* * *} p<0.001$, compared with the corresponding control groups, one-way ANOVA with Newman-Keuls post hoc test. D, Schematic illustration of injection sites in the amygdala of rats used in the experiments ( $\bigcirc$, control;,$Y 27632$ injected before pairing; $\mathbf{\Delta}$, Y27632 injected after pairing). Con, Control; Veh, vehicle.

control, $n=4, F_{(2,11)}=18.82, p=0.0006 ; \mathrm{D}-\mathrm{AP} 5,54.61 \pm$ $12.93 \%$ of control, $n=5, F_{(2,14)}=22.04, p<0.0001$; Fig. $\left.1 A, B\right)$, indicating that amygdalar synaptic actin polymerization is involved in the RhoA-ROCK signaling pathway and depended on NMDA receptor activation.

Our previous study also shows that prevention of actin polymerization by the F-actin polymerization inhibitor latrunculin A suppresses CPA formation (Hou et al., 2009), indicative of the involvement of actin polymerization in CPA formation. We further confirmed this result in the present study by delivering the ROCK inhibitor Y27632 into the amygdala via local microinjection. In support of our previous findings, bilateral microinjection of Y27632 $(8.56 \mu \mathrm{g} / 0.5 \mu \mathrm{l} / \mathrm{side})$ into the amygdala prepairing but not postpairing significantly attenuated place aversion behaviors compared with vehicle-microinjected group (aversion score: vehicle, $-377.0 \pm 61.6 \mathrm{~s}, n=14$; prepairing, $-66.5 \pm 42.6 \mathrm{~s}, n=9$; postpairing, $-312.0 \pm 40.4 \mathrm{~s}$, $n=7 ; F_{(2,29)}=7.139, p=0.0032$; Fig. $\left.1 C\right)$, supporting that amygdalar synaptic actin polymerization is required for CPA formation. Additionally, NMDA-receptor antagonists such as D-AP5 and MK-801 have also been shown to suppress morphine withdrawal-induced CPA formation (Watanabe et al., 2002; Kawasaki et al., 2005). Taken together, the results of our present and previous studies clearly indicate that synaptic actin polymerization within the amygdala plays a critical role in CPA formation, and also show that actin polymerization is dependent on NMDA receptor activation and is involved in the RhoA-ROCK signaling pathway.

Arc/Arg3.1 protein expression was increased in the amygdala in response to both conditioned and unconditioned morphine withdrawal, but its accumulation at synapses was induced only by conditioned morphine withdrawal Arc/Arg3.1 mRNA expression and localization at active synapse are induced by experimental paradigms known to cause synaptic plasticity and memories (Lyford et al., 1995; Steward and Worley, 2001). Enhancement of Arc/Arg3.1 protein at active synapses is critically involved in processes of synaptic plasticity underlying behavioral memories (Guzowski et al., 2000; Plath et al., 2006). Our previous studies also demonstrate that CMW induces the expression of Arc/Arg3.1 protein in the amygdala, mainly in the basolateral nucleus (BLA) and the central nucleus (CeA) (Hou et al., 2009; Li et al., 2009). To address the role of the interaction of Arc/Arg3.1 protein expression and actin polymerization in CPA formation, we first examined colocalization of Arc/Arg3.1 protein with F-actin at amygdalar synapses following CMW. The distribution of Arc/Arg3.1 was analyzed by subcellular fractionation of amygdalar lysates, followed by immunoblotting using Arc/Arg3.1 antibody. PSD-95, a core structural component of the PSD, was used as a marker of synaptic sites. Immunoblotting showed that Arc/Arg3.1 protein highly accumulated in the synaptic fractions of amygdalar lysates (Fig. $2 \mathrm{~A}$ ). The colocalization of Arc/Arg3.1 protein with F-actin was detected by fractionalizing different actin components, followed by immunoblotting using Arc/Arg3.1 antibody. Arc/Arg3.1 protein was found to have high concentrations in the F-actin fractions (Fig. $2 B$ ), confirming that Arc/Arg3.1 colocalized with F-actin at synapses. The results are consistent with previous reports that Arc/Arg3.1 mRNA and protein cosediment with crude filamentous actin (F-actin) and localize at the PSD of excitatory synapses (Lyford et al., 1995; Husi et al., 2000).

Next, we determined whether the colocalization of Arc/Arg3.1 protein with F-actin at synapses was dependent on CMW. To this end, we detected Arc/Arg3.1 protein expression in both amygdalar homogenates and synaptosomal fractions of the amygdala isolated from rats that underwent CMW or unconditioned morphine withdrawal (UMW). A significant elevation of Arc/Arg3.1 protein expression was detected in the amygdalar homogenates isolated from rats 0.5 and $1 \mathrm{~h}$ after CMW (control, $100 \pm 1.97 \%$, $n=6 ; 0.5 \mathrm{~h}, 197.8 \pm 16.8 \%, n=5 ; 1 \mathrm{~h}, 212 \pm 43.1 \%, n=5$; 
A

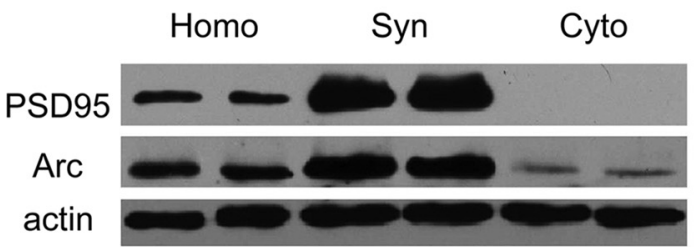

C
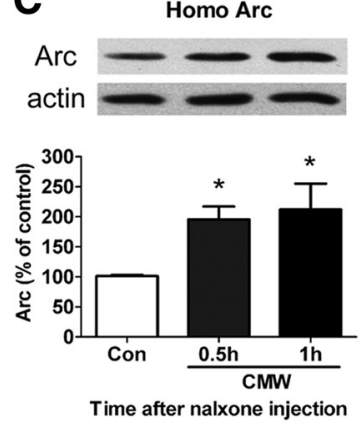
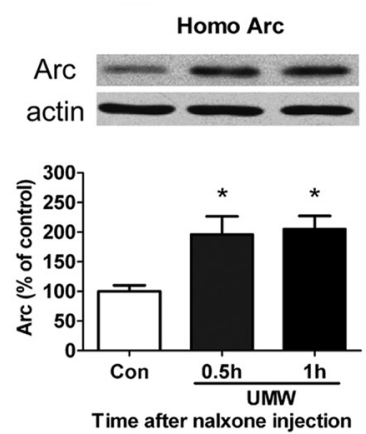

B

\section{Total actin F-actin G-actin}

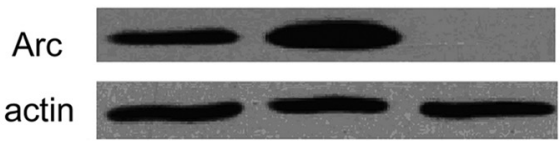

D
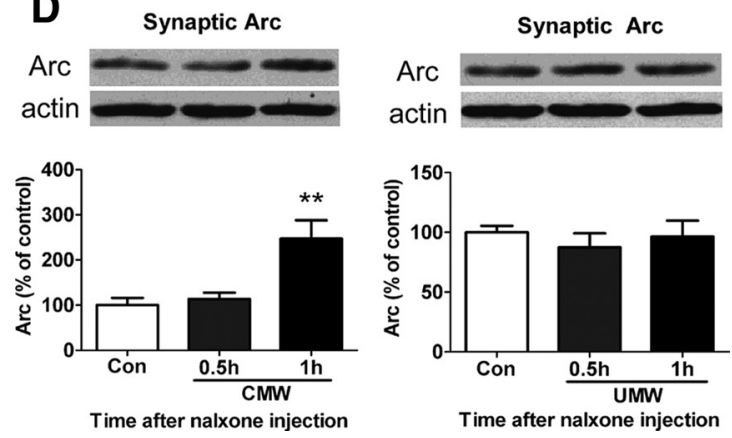

Figure 2. Conditioned morphine withdrawal increased Arc/Arg3.1 protein expression at amygdalar synapses in which it colocalized with F-actin. $\boldsymbol{A}, \boldsymbol{B}$, Arc/Arg3.1 protein was detected in synaptic preparations with PSD95 (A) and displayed cosediment with F-actin but not G-actin (B). Synaptic preparations were from the amygdala of rats $1 \mathrm{~h}$ after $\mathrm{CMW}$ as described in Materials and Methods. C, Enhancement of Arc/Arg3.1 protein expression from the rat amygdalar homogenates 0.5 and $1 \mathrm{~h}$ after both CMW (left) and UMW (right). D, Increase in Arc/Arg3.1 protein expression in the synaptosomal fractions only at $1 \mathrm{~h}$ but not $0.5 \mathrm{~h}$ after CMW (left) but not UMW (right). Error bars represent mean \pm SEM. ${ }^{*} p<0.05$, ${ }^{* *} p<0.01$, compared with the corresponding control groups, one-way ANOVA with Newman-Keuls post hoc test. Homo, Homogenate fraction; Syn, synaptoneurosome fraction; Cyto, cytoplasmic fraction; Con, control.

$F_{(2,15)}=6.324, p=0.0121$; Fig. 2C, left) and UMW (control, $100 \pm 10.0 \% ; 0.5 \mathrm{~h}, 196.0 \pm 30.5 \% ; 1 \mathrm{~h}, 204.9 \pm 22.5 \% ; n=5$, $F_{(2,14)}=6.620, p=0.0115$; Fig. $2 C$, right), indicating that CMW and UMW both induced Arc/Arg3.1 protein expression. However, a significant increase in Arc/Arg3.1 protein expression in the synaptosomal membrane fractions of amygdala was detected only in the rats that underwent CMW (CMW: control, $100 \pm$ $16.2 \% ; 0.5 \mathrm{~h}, 113.5 \pm 14.4 \% ; 1 \mathrm{~h}, 247.6 \pm 40.7 \% ; n=6, F_{(2,17)}=$ 9.398, $p=0.0023$; UMW: control, $100 \pm 5.4 \%, n=5 ; 0.5 \mathrm{~h}$, $87.4 \pm 11.7 \%, n=5 ; 1 \mathrm{~h}, 96.4 \pm 13.4 \%, n=4 ; F_{(2,13)}=0.417, p=$ 0.6688; Fig. $2 D$ ), indicating that CMW but not UMW induced the accumulation of Arc/Arg3.1 protein at synapses, and also suggesting that CMW was required for increase in Arc/Arg3.1 protein at synapses. Additionally, although increase in Arc/ Arg3.1 expression in the amygdala was observed at $0.5 \mathrm{~h}$ after CMW, the accumulation of Arc/Arg3.1 expression at synapses was detected at $1 \mathrm{~h}$ but not $0.5 \mathrm{~h}$ after CMW (Fig. 2D, left), suggesting that there is a process of translocation of Arc/Arg3.1 from neuronal soma to synapses. These results are consistent with previous findings that experimental paradigms known to cause synaptic plasticity and memories trigger translocation of Arc/Arg3.1mRNA to active synapse (Lyford et al., 1995; Steward and Worley, 2001).

\section{Increases in Arc/Arg3.1 protein expression at synapses by} conditional morphine withdrawal was disrupted by blockade of actin polymerization

The data present above demonstrated that both CMW and UMW induced Arc/Arg3.1 protein expression in the amygdala, but only CMW induced the enhancement of Arc/Arg3.1 protein at synapses. Additionally, our previous study also found that CMW but not UMW elicited actin polymerization in the synapses of the amygdala (Hou et al., 2009). Since the F-actin has been shown to serve as a path for local mRNA trafficking within the dendritic spine (Kaech et al., 2001), the elevation of Arc/Arg3.1 protein and actin polymerization occurring in the same synapses in response to CMW raises the possibility that actin polymerization may play a role in the targeting Arc/Arg3.1 mRNA to synapses. To test this hypothesis, we examined the effect of blockade of actin polymerization on accumulation of Arc/Arg3.1 protein at synapses. Since the RhoA kinase inhibitor Y27632, the F-actin polymerization inhibitor latrunculin $\mathrm{A}$, and the NMDA receptor antagonist D-AP5 all abolish actin polymerization induced by CMW (Fig. $1 A, B$ ) (Hou et al., 2009), we thus assessed the effects of local injection of Y27632, latrunculin A, or D-AP5 on accumulation of Arc/Arg3.1 protein at synapses trigged by CMW. As presented in Figure 3, bilateral microinjection of Y27632 $(8.56 \mu \mathrm{g} / 0.5 \mu \mathrm{l} /$ side $)$ or latrunculin A ( $250 \mathrm{ng} / 0.5 \mu \mathrm{l} /$ side $)$ into amygdala $30 \mathrm{~min}$ or 10 min before conditioned pairing blocked the enhancement of Arc/ Arg3.1 protein at synaptosomal membrane fractions of the amygdala induced by CMW ( $A$ : vehicle, $193.5 \pm 32.5 \%$; Y27632, $71.1 \pm 19.7 \%$ of control, $n=5, F_{(2,14)}=6.442, p=0.0126 ; B$ : vehicle, $165.3 \pm 20.3 \%$; Latrunculin A, $87.6 \pm 22.0 \%$ of control, $n=3-4 ; F_{(2,10)}=5.502, p=0.0314$; Fig. $3 A, B$, right panels), but they had no effects on Arc/Arg3.1 protein expression in amygdalar homogenates ( $A$ : vehicle, $219.8 \pm 43.2 \%$; Y27632, $203.5 \pm$ $16.8 \%$ of control, $n=3-4, F_{(2,9)}=7.64, p=0.0174 ; B$ : vehicle, $164.3 \pm 7.43 \%$; Latrunculin A, $174.8 \pm 26.2 \%$ of control, $n=5$, $F_{(2,14)}=6.026, p=0.0154$; Fig. $3 A, B$, left panels).

Next, we determined the effect of NMDA receptor antagonist D-AP5 on CMW-induced increase in Arc/Arg3.1 at amygdalar synapses. As shown in Figure 3, bilateral injection of D-AP5 (4 $\mu \mathrm{g} / 0.5 \mu \mathrm{l} /$ side) into amygdala $10 \mathrm{~min}$ before conditioned pairing resulted in the reduction of Arc/Arg3.1 protein expression both in amygdalar homogenates (vehicle, $184.2 \pm 14.8 \%$; D-AP5, $108.0 \pm 6.2 \%$ of control, $n=4-6, F_{(2,15)}=14.61, p=0.0005$ Fig. $3 C$, left) and in the synaptosomal membrane fractions of amygdala (vehicle, $155.3 \pm 13.7 \%$; D-AP5, $52.7 \pm 13.2 \%$ of control, $n=4-6 ; F_{(2,14)}=23.44, p<0.0001$; Fig. $3 C$, right), consistent with previous finding that NMDA receptor antagonists block the induction of Arc/Arg3.1 mRNA transcription and targeting to dendrites induced by HFS of the perforant path of hippocampus (Steward and Worley, 2001; Huang et al., 2007). Taken together, these results clearly demonstrate that actin po- 
A

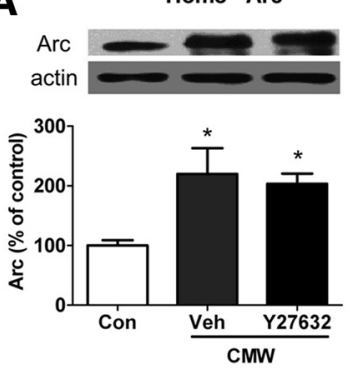

B

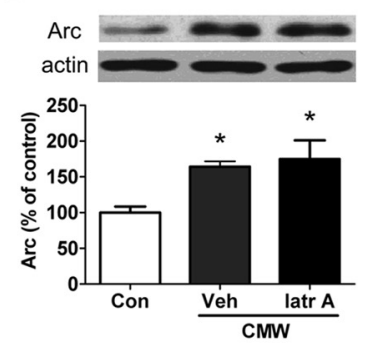

C
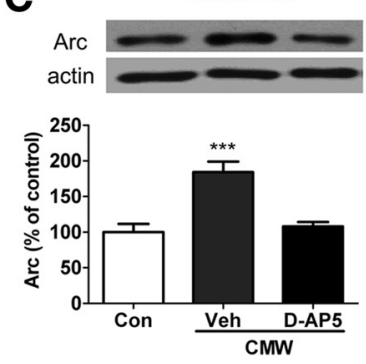

Synaptic Arc
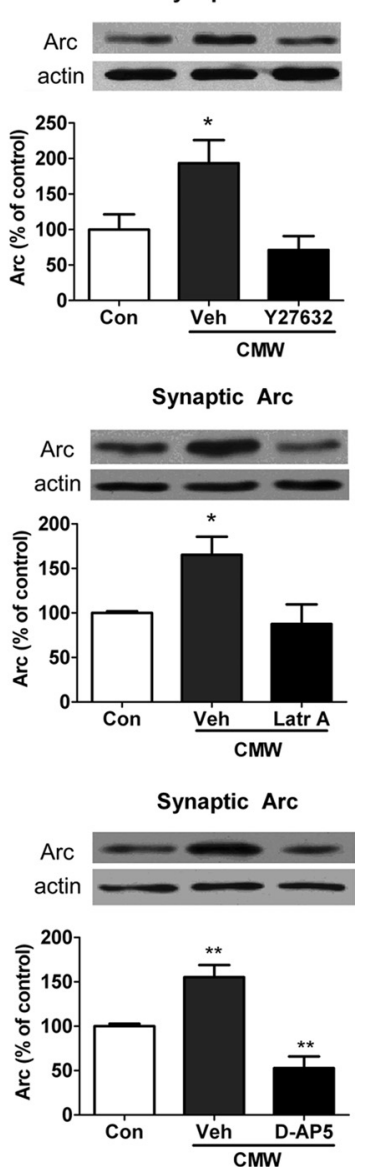

Figure 3. Effects of prepairing intra-amygdala injections of ROCK inhibitor Y27632, actin polymerization inhibitor latrunculin A, or NMDA receptor antagonist D-AP5 on Arc/Arg3.1 protein levels in homogenates and synaptic membrane fractions of amygdala isolated from rats $1 \mathrm{~h}$ after CMW. $\boldsymbol{A}_{\text {, }}$ Intra-amygdala injections of Y27632 blocked enhancement of Arc/Arg3.1 protein expression in the synaptic membrane fractions of amygdala (right), but had no effect on increase in Arc/Arg3.1 protein expression in the homogenates of amygdala (left). $\boldsymbol{B}$, Intra-amygdala injections of latrunculin A attenuated Arc/Arg3.1 expression in the synaptic membrane fractions of amygdala (right), but had no effect on increase in Arc/Arg3.1 protein expression in the homogenates of amygdala (left). C, Intraamygdala injections of the NMDA receptor antagonist D-AP5 blocked enhancement of Arc/Arg3.1 protein expression in both the homogenates (left) and the synaptic membrane fractions (right) of amygdala. Errorbars representmean \pm SEM. ${ }^{*} p<0.05,{ }^{* *} p<0.01$, ${ }^{* * *} p<0.001$, compared with the corresponding control groups, one-way ANOVA with Newman-Keuls post hoc test. Homo, Homogenate fraction; Con, control; Veh, vehicle, Latr, Latrunculin A.

lymerization is required for the targeting of Arc/Arg3.1 to synapses, supporting previous findings that actin polymerization plays a critical role in Arc mRNA targeting to synaptic sites in response to HFS of the dentate gyrus (Huang et al., 2007).

\section{In vivo knockdown of amygdalar Arc/Arg3.1 blocked place aversion behavior induced by conditioned morphine withdrawal}

Substantial evidence demonstrates that Arc/Arg3.1 is necessary for a variety of hippocampus-dependent and -independent memories (Guzowski et al., 2000; Plath et al., 2006). To test whether Arc/Arg3.1 protein is also required for CPA formation, we used a lentivirus expressing short-hairpin (sh) RNA (Arc/Arg3.1-shRNA) to knock down Arc/Arg3.1 mRNA in synapses of the amygdala (Rial Verde et al., 2006). We first in vitro examined the inhibitory effect of Arc/ Arg3.1-shRNA on Arc/Arg3.1 protein expression in rat primarily cultured cortex neurons. Primary cortex neurons were infected with

either control shRNA or Arc/Arg3.1-shRNA in a 20:1 molar ratio. After $12 \mathrm{~h}$ virus infection, the cells were stimulated with forskolin for $3 \mathrm{~h}$ and then harvested for Western blot analysis with Arc/Arg3.1 antibody. As shown in Figure 4, infections of primary cortex neurons with Arc/Arg3.1-shRNA resulted in a significant reduction of Arc/ Arg3.1 protein expression compared with neurons infected with control shRNA (control shRNA, $100 \pm 7.06 \%$; Arc/Arg3.1 shRNA, $\left.13.1 \pm 5.90 \% ; n=5, t_{(8)}=8.948, p<0.0001\right)$ (Fig. $4 A, C$, left).

Next, we examine the effect of in vivo knockdown of Arc/ Arg3.1 protein expression using Arc/Arg3.1-shRNA on CMWinduced place aversion. Animals were received bilateral infusions of lentivirus expressing Arc/Arg3.1-shRNAs with high-titer stocks $\left(5 \times 10^{8}-1 \times 10^{9} \mathrm{TU} / \mathrm{ml}\right)$ or a control shRNAs into the amygdala. Two weeks after virus infusion, the animals were trained using place aversion conditioning paradigm. After CPA test, animals were killed and their brains were isolated and sectioned to slices for detecting the sites infected by virus through visualizing GFP under a fluorescence microscope. It was found that most neurons in the BLA and the CeA of the amygdala were positive for GFP, indicating that bilateral intra-amygdala injections of lentivirus resulted in selective expression of Arc/Arg3.1shRNAs in the BLA and CeA of the amygdala (Fig. 4B). As shown in the right panel of Figure 4C, Arc/Arg3.1-shRNAs-infected animals displayed a significantly lower aversion score than control shRNAs-infected and vehicle-injected animals (aversion score: control shRNA, $-380.9 \pm 31.8 \mathrm{~s}$, Arc/Arg3.1 shRNA, $-86.9 \pm$ $\left.44.7 \mathrm{~s} ; n=12 ; t_{(22)}=5.36, p<0.0001\right)$, indicating that knockdown of Arc/Arg3.1 expression in the amygdala impaired CPA formation. Together, these data demonstrate that Arc/Arg3.1 expression in the amygdala, specifically in the BLA and CeA, may be critically important for CPA formation.

\section{In vivo knockdown of amygdalar Arc/Arg3.1 impaired} conditioned morphine withdrawal-induced AMPA receptor endocytosis

Accumulating data demonstrate that trafficking of AMPARs at synapses plays an important role in the expression of synaptic plasticity (Malinow and Malenka, 2002; Kalivas et al., 2005). F-actin and AMPA receptors are colocalized in dendritic spines (Allison et al., 1998) and postsynaptic F-actin are involved in a dynamic process required to maintain AMPAR-mediated transmission (Kim and Lisman, 1999). Recent in vitro studies in dissociated hippocampal neurons and slice cultures also reveal that Arc/Arg3.1 can modulate AMPA receptor trafficking by facilitating AMPA receptor endocytosis (Chowdhury et al., 2006; Rial Verde et al., 2006; Shepherd et al., 2006). These findings, together with our observations that the newly expressed Arc/Arg3.1 protein colocalizes with F-actin at synapses of the amygdala raise the possibility that actin polymerization may regulate AMPAR trafficking by Arc/Arg3.1-facilitated AMPAR endocytosis and thereby contribute to synaptic plasticity and behavioral adaptations. To investigate the mechanisms by which Arc/Arg3.1 protein contributes to CPA formation, we thus explored whether the Arc/Arg. 31 protein was involved in CMW-induced AMPAR receptor endocytosis. To do this, we first examined the effect of CMW on the distribution of synaptic AMPA receptors in the amygdala using $\mathrm{BS}^{3}$ cross-linking assay (Boudreau and Wolf, 2005). $\mathrm{BS}^{3}$ is a membrane-impermeable protein cross-linking agent and has been shown to selectively cross-link cell surface but not intracellular receptors (Boudreau and Wolf, 2005). As surface receptors and $\mathrm{BS}^{3}$ form high molecular weight aggregates, it can be distinguished using SDS-PAGE and Western blotting. Rats were killed at 0.5 and $1 \mathrm{~h}$ after CMW. Amygdalar tissues were 


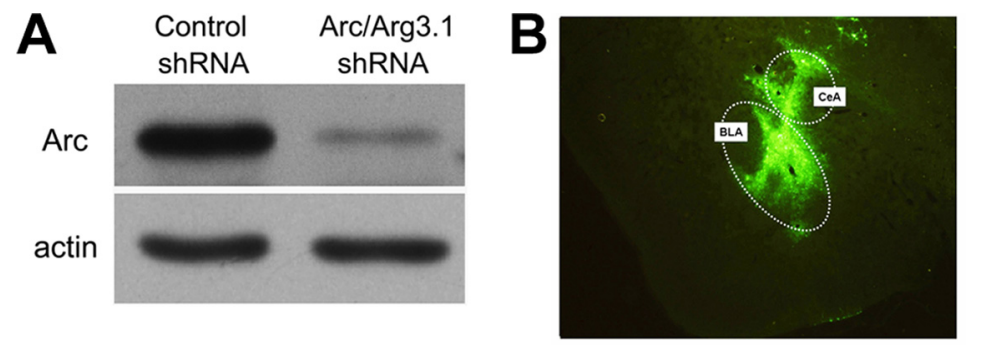

C Arc expression

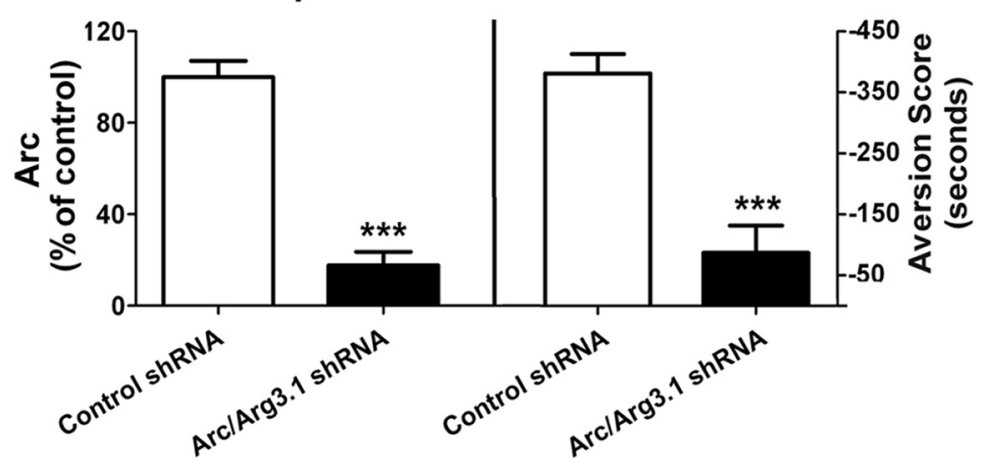

Figure 4. Knockdown of the Arc/Arg3.1 protein in the amygdala abolished conditioned place aversion formation induced by morphine withdrawal. $\boldsymbol{A}$, Representative Western blot image of in vitro knockdown of Arc/Arg3.1 protein expression in primary cortex neurons by Arc/Arg3.1 shRNA. B, Representative image of in vivo lentivirus-infected regions in the amygdala visualized by fluorescence microscope. C, Quantified data of in vitro knockdown of Arc/Arg3.1 protein expression (left) and in vivo knockdown of Arc/Arg3.1 disruption of conditioned place aversion formation (right) by Arc/Arg3.1 shRNA. Error bars represent mean \pm SEM. ${ }^{* * *} p<0.001$, compared with control shRNA- infected groups, two-tailed Student's $t$ test.

isolated and dissected quickly and treated with $\mathrm{BS}^{3}$ as described in Materials and Methods. Immunoblot analysis of AMPARs in cross-linked tissue revealed that the surface to intracellular receptor $(\mathrm{S} / \mathrm{I})$ ratio of GluR1- and GluR2-containing AMPARs were significantly decreased at $1 \mathrm{~h}$ but not at $0.5 \mathrm{~h}$ after CMW (GluR1: control, $100 \pm 6.19 \%, n=11 ; 0.5$ h, $92.2 \pm 10.75 \%, n=5 ; 1 \mathrm{~h}$, $54.7 \pm 12.04 \%, n=11 ; F_{(2,26)}=6.619, p=0.0051$; GluR2: control, $100 \pm 5.04 \%, n=11 ; 0.5 \mathrm{~h}, 102.24 \pm 14.29 \%, n=5 ; 1 \mathrm{~h}$, $59.65 \pm 9.31 \%, n=6 ; F_{(2,21)}=7.383, p=0.0042$; Fig. $5 A, B$, left panels), indicative of a decrease in GluR1- and GluR2-containing AMPAR surface expressions and an increase of their intracellular expressions. No significant differences in the levels of GluR1- and GluR2-containing AMPAR total protein were found between any of the experimental groups, quantified by summing the optical densities of surface and intracellular bands and normalizing to total protein in the lanes (GluR1, $F_{(2,26)}=0.4146, p=0.6652$; GluR2, $F_{(2,21)}=0.4776, p=0.6275$; Fig. $5 A, B$, right panels). These results indicate that endocytosis of GluR1- and GluR2containing AMPAR occurred at $1 \mathrm{~h}$ but not $0.5 \mathrm{~h}$ after CMW.

Next, we examined the effect of in vivo knockdown of Arc/ Arg3.1 protein expression with Arc/Arg3.1-shRNA on CMWinduced GluR1- and GluR2-containing AMPAR endocytosis. Animals received bilateral injections of lentivirus expressing Arc/ Arg3.1-shRNAs with high-titer stocks $\left(5 \times 10^{8}-1 \times 10^{9} \mathrm{TU} / \mathrm{ml}\right)$ or control shRNAs into the amygdala. Two weeks later, all animals were trained using place aversion conditioning paradigm. Rats were killed $1 \mathrm{~h}$ after CMW and $\mathrm{BS}^{3}$ cross-linking assay was used to distinguish surface and intracellular AMPAR pools in the amygdala. As shown in Figure 5, $C$ and $D$, animals expressing Arc/Arg3.1-shRNA exhibited a significant increase in the surface to intracellular ratio for both GluR1-contining AMPARs (control shRNA, $100 \pm 9.90 \%$; Arc/Arg3.1 shRNA, $192.01 \pm 12.18 \%$; $n=$ conditioned morphine withdrawal

$\left.5, t_{(8)}=5.863, p=0.00038\right)$ and GluR2containing AMPARs (control shRNA, $100 \pm 17.68 \%$; Arc/Arg3.1 shRNA, $202.31 \pm 15.54 \% ; n=5, t_{(8)}=4.346, p=$ 0.00246), when compared with animals expressing control shRNAs. No differences of total AMPARs expression were detected between any of the experimental groups, quantified by summing the optical densities of surface and intracellular bands and normalizing to total protein in the lanes (GluR1, $t_{(8)}=0.8317, p=0.43$; $\left.\mathrm{GluR}_{2}, t_{(8)}=1.073, p=0.31\right)$. These results demonstrate that the knockdown of synaptic Arc/Arg3.1 with Arc/Arg3.1shRNAs reduces AMPAR endocytosis, supporting the idea that Arc/Arg3.1 plays an essential role in regulation of AMPAR endocytosis in response to CMW. Thus, in agreement with previous observations in vitro (Chowdhury et al., 2006; Rial Verde et al., 2006; Shepherd et al., 2006), the present study demonstrates that Arc/Arg3.1 also modulates AMPAR trafficking by facilitating AMPA receptor endocytosis in vivo.

Intra-amygdala injection of

Tat-GluR2 3 , a GluR2-derived peptide, prevented both the formation of conditioned place aversion and the endocytosis of AMPARs induced by

The findings that in vivo knockdown of Arc/Arg3.1 with Arc/ Arg3.1-shRNA disrupts CPA formation and blocks GluR1- and GluR2-containing AMPAR endocytosis imply that AMPAR endocytosis may be tightly implicated in CPA formation. To confirm that the disruption of CPA by Arg/Arg3.1 shRNA is attributed to its prevention of AMPAR endocytosis, we determined the role of AMPAR endocytosis in CPA formation using a synthetic peptide derived from rat GluR2 carboxyl tail (TatGluR2 $2_{3 Y}$ : YGRKKRRQRRRYKEGYNVYG), which has been shown to specifically block regulated, but not constitutive, AMPAR endocytosis (Ahmadian et al., 2004). We first determined whether AMPARs were implicated in CPA formation. Rats were bilaterally injected with vehicle or AMPAR antagonist CNQX into amygdala $10 \mathrm{~min}$ before CMW. Animals injected with CNQX (30 nmol/0.5 $\mu \mathrm{l} /$ side) exhibited a significantly lower place aversion score relative to those injected with vehicle (aversion score: vehicle, $-285.4 \pm 30.9 \mathrm{~s}, n=8$; CNQX, $-62.7 \pm 36.4 \mathrm{~s}$, $n=10 ; t_{(16)}=4.523, p=0.00035$; data not show), indicating that AMPARs play a crucial role in the formation of CPA, consistent with previous studies that local or systematic injection of CNQX could suppress CPA behaviors (Watanabe et al., 2002; Kawasaki et al., 2005).

Next, we determined whether AMPAR endocytosis was required for CPA formation. To do this, we tested the effect of intra-amygdala injection of Tat-GluR2 $2_{3 Y}$ on CPA formation. Bilateral intra-amygdala injection of Tat-GluR2 $2_{3 Y}(15 \mathrm{pmol} /$ $0.5 \mu \mathrm{l} /$ side) $1 \mathrm{~h}$ before conditioned pairing yielded a significant reduction of place aversion scores compared with bilateral intraamygdala injection of inactive control peptide Tat-GluR2 35 (aversion score: Tat-GluR2 ${ }_{3 \mathrm{~S}},-308.5 \pm 26.9 \mathrm{~s}, n=13$; TatGluR2 $_{3 Y},-92.3 \pm 23.1 \mathrm{~s}, n=14 ; t_{(25)}=6.117, p<0.0001$; Fig. 
$6 A$ ), indicative of a critical role of AMPAR endocytosis in CPA formation. The results are consistent with previous studies that Tat-GluR2 $2_{3 Y}$ suppressed drugs of abuse-induced associative learning such as behavior sensitization and cue-induced drug relapse to drug seeking (Brebner et al., 2005; Van den Oever et al., 2008).

To further confirm that disruption of CPA formation by Tat-GluR2 $2_{3 Y}$ is attributed to its blockade of GluR2-containg AMPAR endocytosis, next, we examined the effect of Tat-GluR2 3 on the endocytosis of GluR2-containing AMPARs induced by CMW. As shown in Figure 6B, indeed, bilateral intra-amygdala injection of Tat-GluR2 $2_{3 Y}(15 \mathrm{pmol} / 0.5 \mu \mathrm{l} / \mathrm{side})$ but not inactive control peptide GluR2 $2_{3 S} 60$ min before CMW completely abolished the endocytosis of GluR2-containing AMPARs (Tat-GluR2 3 s, $52.77 \pm 5.45 \%$; Tat-GluR2 ${ }_{3 Y}, 97.11 \pm 17.89 \%$ of control, $\left.n=5-6 ; F_{(2,15)}=5.229, p=0.0216\right) . \mathrm{CMW}$ also led to endocytosis of GluR1-containg AMPARs and this effect could be blocked by knockdown of Arc/Arg3.1 protein with Arc/ Arg3.1-shRNA (Fig. 5). Since endogenous GluR1 and GluR2 subunits emerge mainly as GluR1/GluR2 heteromers (Wenthold et al., 1996) and GluR2 acts as dominant subunits to control regulated GluR1/GluR2 heteromeric AMPAR endocytosis (Ahmadian et al., 2004; Lee et al., 2004; Isaac et al., 2007), we thus tested the effect of Tat-GluR2 3 Y on CMW-induced GluR1containg AMPA endocytosis. As expected, bilateral intra-amygdala injection of TatGluR2 ${ }_{3 Y}(15 \mathrm{pmol} / 0.5 \mu \mathrm{l} / \mathrm{side})$ but not inactive control peptide GluR2 ${ }_{3 S} 60$ min before CMW also completely abolished the endocytosis of GluR1-containing AMPARs (TatGluR2 $_{3 S}, 50.06 \pm 9.27 \%$; Tat-GluR2 ${ }_{3 Y}, 117.23 \pm 23.20 \%$ of control, $n=5-7 ; F_{(2,16)}=5.405, p=0.0182$ ) (Fig. 6C). No significant differences in the levels of GluR1 and GluR2 total protein were found between any of the experimental groups, quantified by summing the optical densities of surface and intracellular bands and normalizing to total protein in the lanes (GluR1, $F_{(2,16)}=0.1140, p=0.8930$; GluR2, $F_{(2,15)}=0.9024, p=0.4296$; Fig. $\left.6 B, C\right)$. These results confirm that AMPARs endocytosis was indeed blocked by Tat-GluR2 $2_{3 Y}$.

Tat-GluR2 ${ }_{3 Y}$ peptide does not alter GluR2 or GluR1 surface expression under baseline conditions and has no effects on Arc/Arg3.1 protein expression and translocation

To confirm that Tat-GluR2 $2_{3 Y}$ peptide specifically acts on AMPAR itself but not on upstream molecules of AMPAR internalization and has no effect on AMPAR surface expression under baseline conditions, we thus tested whether GluR2 or GluR1 surface expressions were altered with Tat-GluR2 $2_{3 Y}$ injection in the absence of CMW and whether Arc expression and synaptic translocation are still induced by CMW in the presence of Tat-GluR2 ${ }_{3 y}$ peptide. Naive rats were injected with Tat-GluR2 ${ }_{3 Y}$ peptide into the amygdala and killed after $2 \mathrm{~h}$. Isolated amygdalar tissues were used for $\mathrm{BS}^{3}$ cross-linking and Western blotting analysis. One-way ANOVA analysis showed no
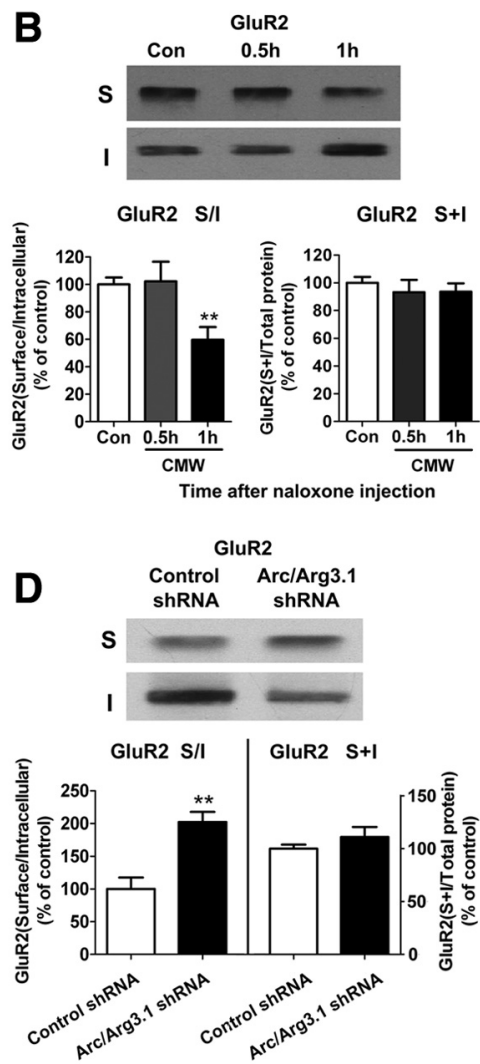

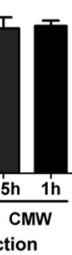

\section{GluR1}

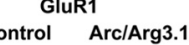

$\begin{array}{lr}\text { Control } & \text { Arc/Arg } 3.1 \\ \text { shRNA } & \text { shRNA }\end{array}$
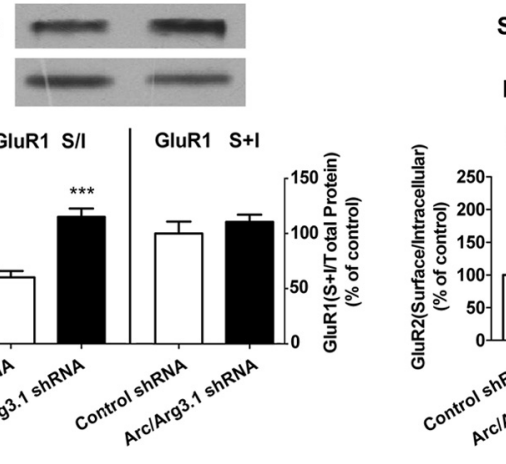

Figure 5. Knockdown of the Arc/Arg3.1 protein in the amygdala inhibited GluR1- and GluR2-containing AMPAR endocytosis induced by CMW. $\boldsymbol{A}, \boldsymbol{B}, \mathrm{CMW}$ resulted in reduction of surface GluR1- and GluR2-containing AMPARs. Top panels show representares GluR2-containing AMPARs levels from Western blot data. Error bars represent mean \pm SEM. ${ }^{* *} p<0.01$, compared with the Arc/Arg3.1 inhibited decreases in surface GluR1- and GluR2-containing AMPARs induced by CMW. Top panels show representative

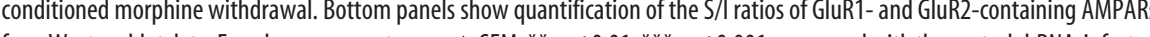
列 groups, two-tailed Student's $t$ test. Total proteins $(S+I$, normalized to total protein in the lane) levels of GluR1- and GluR2containing AMPARs have no changes in all groups.

significant differences in the levels of GluR2 (Fig. 7A) or GluR1 (Fig. 7B) $\mathrm{S} / \mathrm{I}$ ratio between any of the experimental groups $\left(\mathrm{GluR} 2, F_{(2,16)}=\right.$ $0.4068, p=0.6734, n=5-6$; GluR1, $F_{(2,17)}=0.2854, p=0.7557, n=$ $6)$. These results confirm that preinjection of Tat-GluR2 $2_{3 Y}$ peptide into the amygdala have no effects on both GluR2- and GluR1-containing AMPAR surface expression under baseline conditions.

Since in vivo knockdown of amygdalar Arc/Arg3.1 with Arc/ Arg3.1-shRNA also prevented GluR1- and GluR2-containing AMPAR endocytosis (Fig. 5C,D), it raises the possibility that the blockade of AMPAR endocytosis by Tat-GluR2 ${ }_{3 Y}$ peptide might be induced by altering expression or synaptic translocation of Arc/Arg3.1 protein. Thus, we next tested whether Arc/Arg3.1 was still expressed and driven into synaptic compartments of the amygdala in the presence of the GluR2 peptide during conditioned opiate withdrawal. As shown in Figure 7, $C$ and $D$, a significant increase in Arc/Arg3.1 protein expression was detected in both the homogenates $\left(F_{(3,20)}=4.408, p=0.0181, n=5-6\right)$ and synaptosomal membrane fractions $\left(F_{(3,20)}=6.136, p=0.0051\right.$, $n=5-6)$ of the amygdala in the presence of the Tat-GluR2 ${ }_{3 Y}$ peptide during conditioned opiate withdrawal. This indicates that preinjection of Tat-GluR2 $2_{3 Y}$ peptide into the amygdala have no effects on both Arc/Arg3.1 protein expression and transloca- 
A

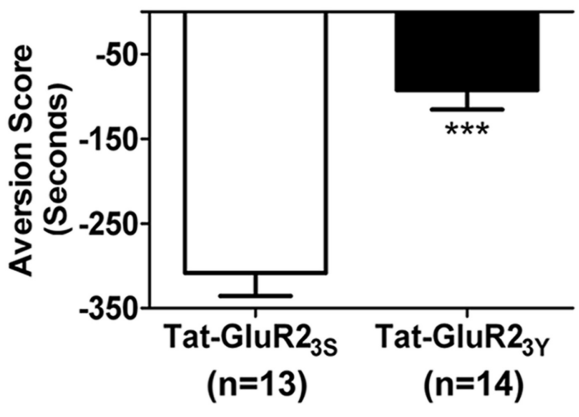

B

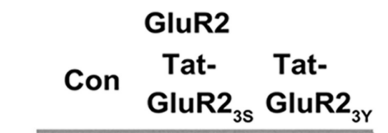

s

I
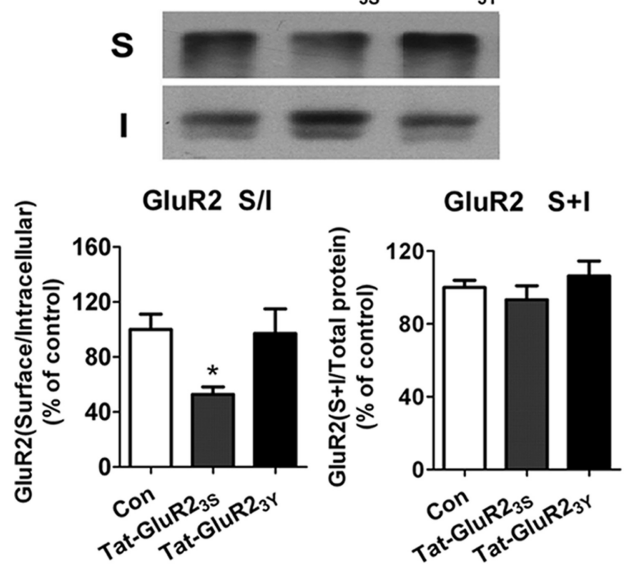

\section{Bregma}

$-2.56$

$-2.80$

$-3.14$
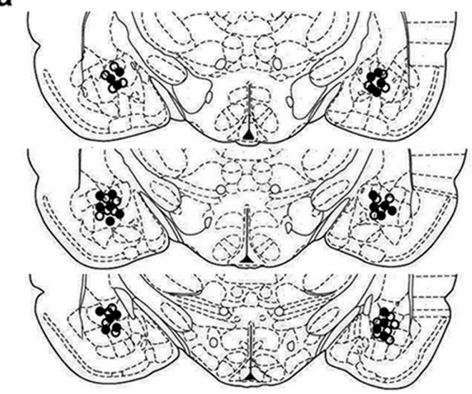

C

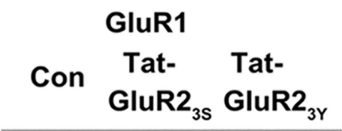

S
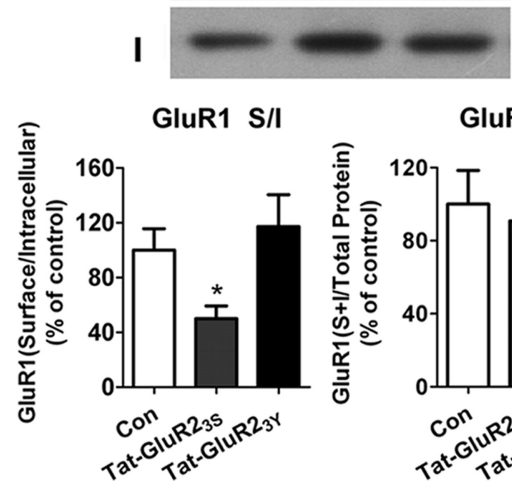

GluR1 S+I

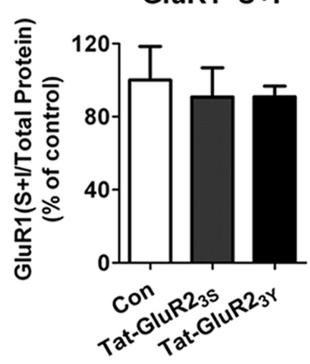

Figure 6. Intra-amygdala injections of Tat-GluR2 ${ }_{3 Y}$ prevented the formation of conditioned place aversion and the endocytosis of GluR1- and GluR2-containing AMPARs induced by conditioned morphine withdrawal. $A$, Left, Bilateral microinjection of Tat-GluR2 $2_{3 Y}$ but not Tat-GluR2 35 into the amygdala blocked CPA formation induced by CMW; right, the image of schematic illustration of Tat-GluR2 ${ }_{35}$ and Tat-GluR2 $2_{3 \gamma}$ injection sites in the amygdala. $\bigcirc$, Tat-GluR2 ${ }_{35}$ injection; $\boldsymbol{O}$, Tat-GluR2 $2_{3 \gamma}$ injection. Error bars represent mean \pm SEM. ${ }^{* * *} p<0.001$, compared with the Tat-GluR2 $3 S^{-}$ injected groups, two-tailed Student's t test. $\boldsymbol{B}, \boldsymbol{C}$, Tat-GluR2 ${ }_{3 \gamma}$ peptide prevented the endocytosis of GluR2-and GluR1-containing AMPARs induced by conditioned morphine withdrawal. Top panels show representative blots of surface (S) and internalized (I) GluR2- and GluR1-containing AMPARs from amygdalar tissues prepared from rats $1 \mathrm{~h}$ after conditioned morphine withdrawal. Bottom panels show quantification of surface/internal GluR2-and GluR1-containing AMPARs levels from Western blot data. Error bars represent mean \pm SEM. ${ }^{*} p<0.05$, compared with the corresponding saline-treated control group, one-way ANOVA with Newman-Keuls post hoc test.

tion to synaptic compartments of the amygdala, suggesting that Tat-GluR2 ${ }_{3 y}$ peptide specifically acts on AMPARs.

\section{Conditioned morphine withdrawal elicited occlusion of long-} term depression in the amygdala

Our data indicate that CMW induces endocytosis of AMPARs through a mechanism involving an increase in Arc/Arg3.1 expression. Endocytosis of AMPARs usually results in the expression of various forms of LTD in various brain areas (Brebner et al., 2005; Yu et al., 2008). Hence, we hypothesize that CMW may induce a form of LTD, which may prevent or occlude further induction of LTD in response to stimulus. To test this hypothesis, we measured excitatory synaptic transmission in slices of the amygdala prepared from rats in which CPA was induced by CMW. As shown in Figure 8A, reliable LTD was induced by LFS ( $1 \mathrm{~Hz}, 900$ pulses) in the amygdalar slices prepared from naive rats $(83.15 \pm 6.07 \%, 14$ slices from seven rats). Preincubation of slices with the Tat-GluR2 $2_{3 Y}$ peptide $(1.5 \mu \mathrm{M})$, while not affecting basal synaptic transmission (data not shown), prevented the expression of LTD (102.15 $\pm 1.95 \%$, eight slices from five rats). The control inactive peptide Tat-GluR2 $2_{35}$ failed to affect LTD $(76.50 \pm 11.81 \%$, six slices from three rats). These results are consistent with previous studies showing that the Tat-GluR2 $2_{3 Y}$ peptide prevent the regulated, but not constitutive AMPAR en- docytosis (Ahmadian et al., 2004) and thereby block the expression of LTD, without affecting the basal synaptic transmission (Ahmadian et al., 2004; Brebner et al., 2005; Yu et al., 2008), and support the idea that LFS-induced LTD relies on endocytosis of GluR2-containg AMPARs (Ahmadian et al., 2004; Rial Verde et al., 2006). LFS also induced LTD in the slices prepared from the rats that underwent UMW $(89.40 \pm 4.64 \%$, nine slices from four rats) or saline-pairing control rats $(80.48 \pm 14.48 \%$, eight slices of five rats; Fig. $8 B$ ). However, LFS failed to induce LTD in the amygdalar slices from rats that underwent CMW (101.43 \pm $8.87 \%$, six slices from five rats; Fig. $8 C$ ), consistent with the idea that CMW induces a form of LTD that would occlude further induction of LTD by LFS if the LTDs share similar mechanisms. CMW induces GluR2-containing AMPAR endocytosis via Arc/ Arg3.1-dependent mechanism (Fig. 5), implying that it may induce an LTD via GluR2-dependent endocytosis of AMPARs. If this is the case, blockade of the CMW-induced LTD with TatGluR2 $2_{3 Y}$, which show blockade of LTD expression, without affecting either the basal synaptic transmission or the expression of LTP in various brain areas (Ahmadian et al., 2004; Brebner et al., 2005), could restore the LFS-induced LTD. As predicated, LFS elicited a reliable LTD in the amygdalar slices prepared from the rats that were injected Tat-GluR2 $2_{3 \mathrm{Y}}$ intravenously $(15 \mu \mathrm{mol} / \mathrm{kg}$, i.v.) 24 h before CMW (74.16 $\pm 5.87 \%$, nine slices of four rats; 
Fig. $8 D$ ). However, LFS was unable to induce LTD in the amygdalar slices prepared from rats that were injected with the inactive control peptide GluR2 3 before CMW (105.99 $\pm 12.82 \%$, 10 slices from four rats; Fig. $8 D$ ). These results strongly support that CMW elicits an LTD in the amygdala via endocytosis of GluR2containg AMPARs as a result of enhancement of Arc/Arg3.1 protein expression and suggest that like other forms of experiencedependent behavioral plasticity, CPA behavior may be due, at least in part, to modifications of synaptic efficacy in critical neural circuits. Overall, our results, together with the observations that intra-amygdala injection of Tat-GluR2 $2_{3 Y}$ also disrupts CMW-induced CPA, suggest that the mechanisms that modulate LTD are critical for CPA formation.

\section{Discussion}

Synaptic actin rearrangements have been shown to play a crucial role in the stabilization of synaptic plasticity and the formation of long-term memory (Matus, 2000; Marie-Claire et al., 2004). However, molecular mechanisms underlying actin polymerization in regulation of synaptic plasticity and memory remain unclear. In this study, by using CPA, a model for associative learning, we provided the first in vivo evidence that behavior training triggers Arc/Arg3.1 translocation at the synapses through actin polymerization, and Arc/Arg3.1 in turn regulates synaptic AMPA receptor endocytosis, thereby leading to amygdalar synaptic depression and aversive memory formation. Actin rearrangement, Arc/Arg3.1 expression, and AMPA receptor trafficking are three critical molecular events involved in synaptic plasticity and memory formation. The present study reveals for the first time that Arc/ Arg3.1 is a crucial mediator for actin polymerization in regulating synaptic plasticity and memory, and thus our findings underscore the unknown details of how actin polymerization mediates synaptic plasticity and memory.

Actin polymerization is required for the enhancement of Arc/ Arg3.1 protein expression at Amygdalar synapses

Recently, we showed that synaptic actin polymerization in the amygdala was required for aversive memory information (Hou et al., 2009). However, the molecular mechanisms by which actin polymerization contributes to the aversive memories of morphine withdrawal remain to be established. The present study demonstrated that actin polymerization was involved in the enhancement of Arc/Arg3.1 protein expression at amygdalar synapses in response to CMW. This involvement was supported by the following observations. First, synaptic enhancement of Arc/ Arg3.1 protein occurred later than that of synaptic actin polymerization. Actin polymerization within synapses occurred at $0.5 \mathrm{~h}$ after CMW (Hou et al., 2009) (Fig. 1); however, increased Arc/ with Newman-Keuls post hoc test.
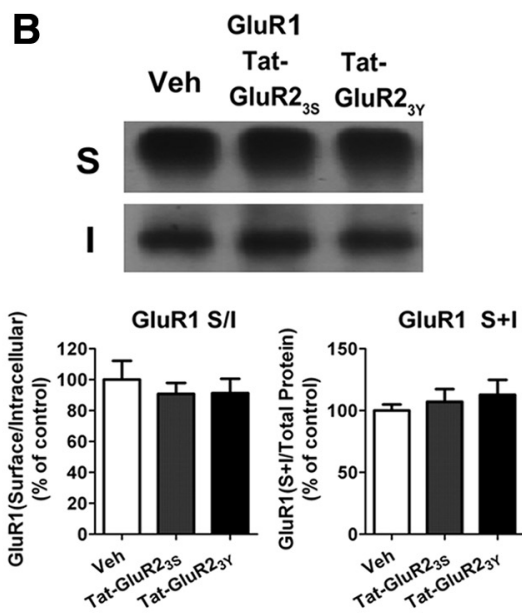

GluR2 S+1

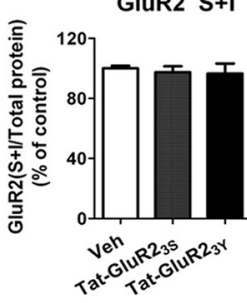

D

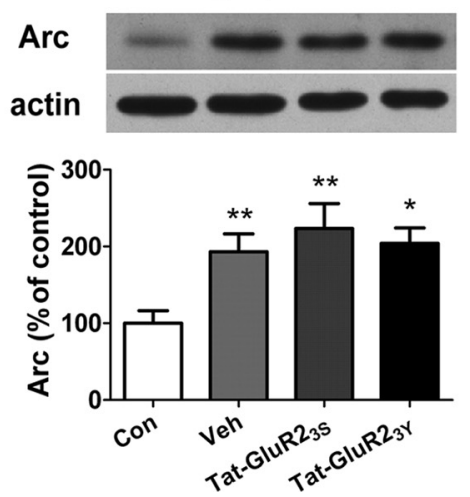

Figure 7. Tat-GluR2 $2_{3 Y}$ peptide does not alter GluR2 or GluR1 surface expression under baseline conditions and has no effects on 作 mygdalar tissues prepared from rats $2 \mathrm{~h}$ after injection. Bottom panels show quantification of surface/internal GluR2- and

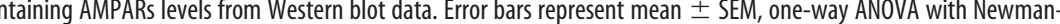
show representative blots of Arc/Arg3.1 protein levels in the homogenates and the synaptosomal membrane fractions prepared from amygdalar tissues prepared from rats $1 \mathrm{~h}$ after conditioned morphine withdrawal. Bottom panels show quantification of represent mean \pm SEM. ${ }^{*} p<0.05,{ }^{* *} p<0.01$, compared with the corresponding saline-treated control group, one-way ANOVA

Arg3.1 protein at synapses could be examined only at $1 \mathrm{~h}$ after CMW (Fig. 2D), although increase in Arc/Arg3.1 protein expression in the amygdala was observed at $0.5 \mathrm{~h}$. This suggests a translocation of Arc mRNA from soma to synapse. Second, prior to conditioned pairing of intra-amygdala injection of D-AP5, an NMDA receptor antagonist that blocked actin polymerization (Fig. 1B) (Huang et al., 2007), also disrupted the enhancement of Arc/ Arg3.1 protein in the synaptic sites (Fig. 3C). Third, direct evidence to support the involvement of actin polymerization in the enhancement of Arc/Arg3.1 protein in the synaptic sites was that blockade of actin polymerization with RhoA kinase inhibitor Y27632 and the F-actin polymerization inhibitor latrunculin A abolished the enhancement of Arc/Arg3.1 protein at the amygdalar synapses (Fig. $3 A, B)$. These results clearly indicate that actin polymerization are required for the targeting of Arc/Arg3.1 mRNA to synapses in response to conditioned pairing, consistent with a previous study showing that actin polymerization plays a critical role in Arc mRNA targeting to active synapse in response to HFS known to cause LTP (Huang et al., 2007). Intriguingly, a recent study shows that Arc/ 

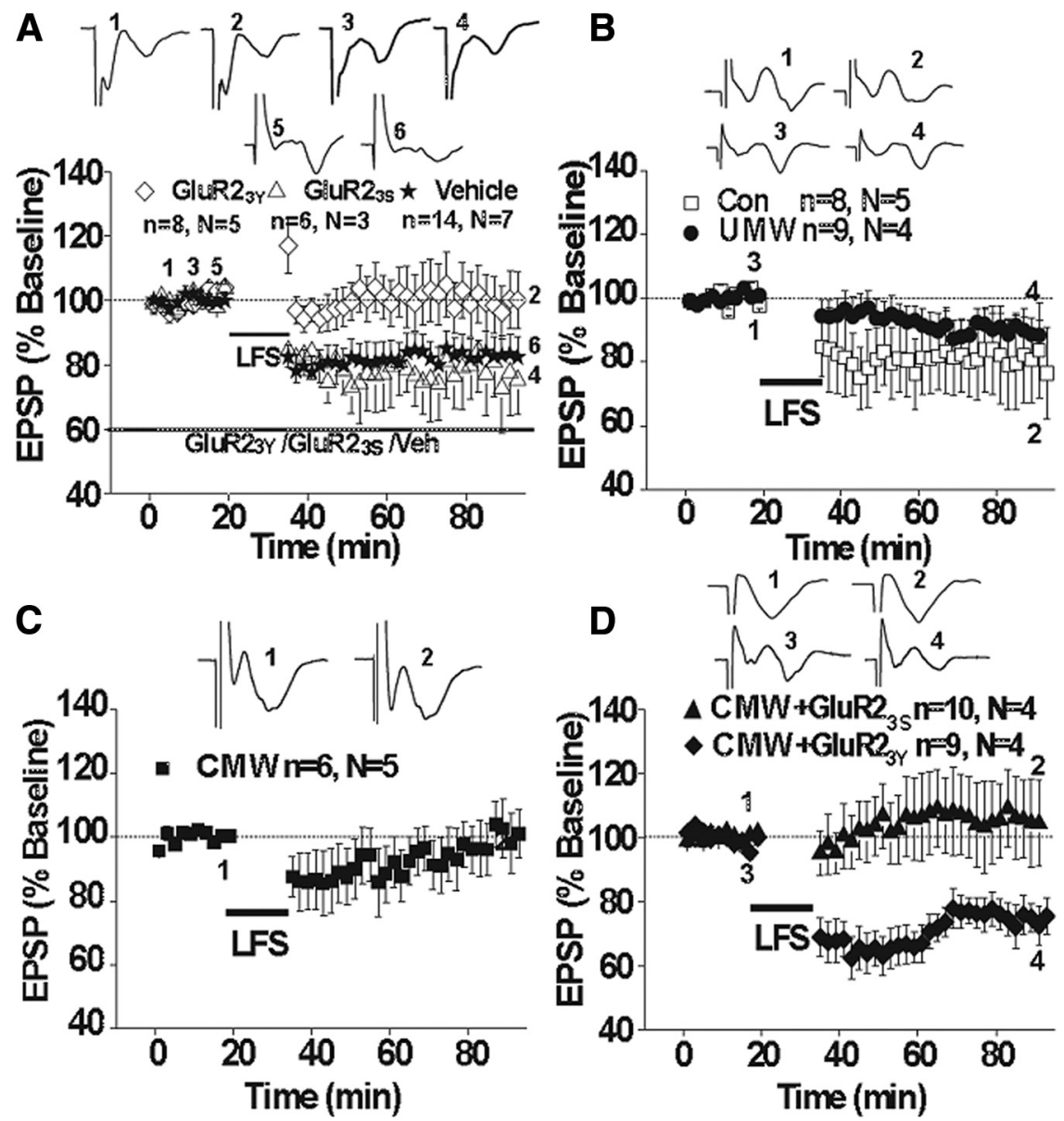

Figure 8. LFS-elicited LTD was occluded by conditioned morphine withdrawal. $A$, LFS-LTD can be induced in naive rats $\left({ }^{*}\right)$ and blocked by Tat-GluR2 3 $(\diamond)$ but not Tat-GluR2 $35(\triangle)$. $\boldsymbol{B}$, LFS-LTD also can be induced in saline pairing control $(\boldsymbol{B}, \square)$ and unconditioned morphine withdrawal $(\boldsymbol{B}, \boldsymbol{O})$ rats. $\boldsymbol{C}, \boldsymbol{D}$, LFS-LTD is blocked in conditioned morphine withdrawal rats $(\boldsymbol{C})$ and is rescued by Tat-GluR2 $2_{3 Y} 24 \mathrm{~h}$ before conditioned morphine withdrawal $(\boldsymbol{D}, \mathbf{\Delta})$ but not Tat-GluR2 ${ }_{3 S}(\boldsymbol{D}, \mathbf{\Delta})$. Insets are the representative examples of each group.

Arg3.1 protein was also required for stabilization of F-actin in the dentate gyrus during LTP induced by HFS (Messaoudi et al., 2007), suggesting a possible positive feedback loop.

Accumulated Arc/Arg3.1 protein at amygdalar synapses promotes GluR1- and GluR2-containing AMPAR endocytosis in a GluR2-dependent manner

Although accumulating evidence demonstrates a crucial role of Arc/Arg3.1 in stabilization of synaptic plasticity and long-term memory formation (Guzowski et al., 2000; Plath et al., 2006), the precise mechanism by which Arc/Arg.3.1 contributes to synaptic plasticity and memory formation is currently unknown. Regulation of AMPAR trafficking is known to be critical for synaptic plasticity (Malinow and Malenka, 2002; Anggono and Huganir, 2012). Recent studies performed in dissociated hippocampal neurons and organotypic slice cultures have demonstrated that Arc/Arg3.1 mediates AMPAR endocytosis by interacting with endophilin and dynamin (Chowdhury et al., 2006). The activity-dependent expression of Arc/Arg3.1 mRNA underlaid a homeostatic mechanism that maintains a precise level of AMPAR-dependent excitability in conditions of persistently increased or decreased synaptic input (Rial Verde et al., 2006; Shepherd et al., 2006). However, it remains unclear whether similar promotion of AMPAR endocytosis by Arc/Arg3.1 also occurs in vivo in response to stimulus known to cause synaptic plasticity and memory and whether regulation of AMPAR endocytosis in vivo by Arc/Arg3.1 contributes to synaptic plasticity and memory formation.

The present study demonstrated that synaptic Arc/Arg3.1 protein expression was required for CMW-induced decreases in surface GluR1- and GluR2-containing AMPAR expression, as knockdown of synaptic Arc/Arg3.1 protein expression with Arc/Arg3.1-shRNA but not control shRNA failed to induce GluR1- and GluR2containing AMPAR endocytosis in response to CMW. Additional evidence in support of a role of Arc/Arg3.1 in GluR1- and GluR2containing AMPAR endocytosis was that GluR1 - and GluR2-containing AMPAR endocytosis occurred at $1 \mathrm{~h}$ but not $0.5 \mathrm{~h}$ after CMW, consistent with synaptic accumulation of Arc/Arg3.1 occurrence at $1 \mathrm{~h}$ but not $0.5 \mathrm{~h}$. Our findings suggest that in vivo Arc/ Arg3.1 also modulates AMPAR trafficking by facilitating AMPAR endocytosis. We further found that the endocytosis of AMPARs induced by CMW was GluR2-dependent, as prior to conditioned pairing bilateral intraamygdala injection of a GluR2-derived peptide, Tat-GluR2 $2_{3 Y}$ that has been shown to specifically block regulated, but not constitutive, AMPAR endocytosis (Ahmadian et al., 2004), completely abolished the endocytosis of GluR1 and GluR2-containing AMPARs. This is consistent with previous findings that GluR2 acts as dominant subunit to control regulated endocytosis (Ahmadian et al., 2004; Lee et al., 2004; Isaac et al., 2007) and that Arc/ Arg3.1 promotes GluR2-containing AMPAR endocytosis in the organotypic hippocampal slices and cultured hippocampal neurons (Rial Verde et al., 2006; Shepherd et al., 2006).

Arc/Arg3.1 protein-mediated AMPAR endocytosis is crucial for amygdalar long-term depression and the expression of conditioned place aversion

At excitatory synapses in the central nervous system, AMPARs are responsible for most synaptic transmission. Activitydependent regulation of AMPAR number at synapses is a principal mechanism for some forms of behavioral plasticity (Rumpel et al., 2005; Clem et al., 2010). It has been shown that removal of AMPARs from synapses is required for relapse to drug-seeking and behavioral sensitization (Brebner et al., 2005; Van den Oever et al., 2008). Consistent with these studies, we found that GluR2dependent AMPAR endocytosis was required for CPA formation, as bilateral intra-amygdala injection of Tat-GluR2 $2_{3 \mathrm{Y}}$ prior to conditioned pairing prevented morphine withdrawal-induced CPA in the rats, indicative of a critical role of GluR2-dependent AMPAR endocytosis in CPA formation. Moreover, we demonstrated that in vivo knockdown of amygdalar Arc/Arg3.1 with Arc/Arg3.1-shRNA blocked both GluR2-dependent AMPAR endocytosis and CPA formation, suggesting that Arc/Arg3.1mediated AMPAR endocytosis plays a critical role in CPA 
formation. Our findings are consistent with previous studies showing that AMPAR endocytosis plays a crucial role in some forms of behavior adaptations induced by drug exposure but extend these findings by revealing a role of Arc/Arg3.1 in AMPAR endocytosis.

In this study, we also found that CMW resulted in occlusion of LTD induction in the amygdala and this occlusion was rescued by intravenous injection of Tat-GluR2 $2_{3 Y}$ before conditioned pairing. These results suggest that LTD, expressed via a decrease in synaptic AMPARs through GluR2-dependetn endocytosis, occurs in amygdalar neurons as a result of enhancement of synaptic Arc/Arg3.1 expression. The findings, together with the observations that intra-amygdala injection of Tat-GluR $2_{3 Y}$ before conditioned pairing prevented the expressions of both LTD and CPA, provides an evidence for the involvement of GluR2 endocytosismediated LTD within the amygdala in the acquisition of aversive memory associated with morphine withdrawal. This is different from the findings obtained from fear memory, another amygdalar-dependent emotional learning, in which the mechanisms of LTP are recruited (Tsvetkov et al., 2002; Maren, 2005). In support of our findings, GluR2 endocytosis-mediated LTD within the nucleus accumbens and the prefrontal cortex is linked to some forms of experience-dependent behavioral plasticity such as behavioral sensitization (Thomas et al., 2001; Brebner et al., 2005) and cue-induced relapse to heroin-seeking (Van den Oever et al., 2008). Therefore, the studies of us and others suggest that LTD may be required for some forms of drug-associated memory formation. Overall, the present study reveals that Arc/ Arg3.1-mediated AMPAR endocytosis and the resulting synaptic depression in amygdala is crucial for the formation of aversive memory associated with morphine withdrawal and thereby suggests that amygdala can contribute to the formation of aversive memories by distinct mechanisms.

In summary, we demonstrate that essential molecular events occurred at amygdalar synapses for aversive memories associated with drug withdrawal, which are initiated by activation of NMDA receptors, leading to fast increase of actin polymerization to help the increase of Arc/Arg3.1 protein at synaptic sites, and thereby enabling LTD and memory formation by Arc/Arg3.1-mediated AMPAR endocytosis. These findings underscore a part of the details of how actin rearrangements contribute to synaptic plasticity and long-term memory.

\section{References}

Ahmadian G, Ju W, Liu L, Wyszynski M, Lee SH, Dunah AW, Taghibiglou C, Wang Y, Lu J, Wong TP, Sheng M, Wang YT (2004) Tyrosine phosphorylation of GluR2 is required for insulin-stimulated AMPA receptor endocytosis and LTD. EMBO J 23:1040-1050.

Allison DW, Gelfand VI, Spector I, Craig AM (1998) Role of actin in anchoring postsynaptic receptors in cultured hippocampal neurons: differential attachment of NMDA versus AMPA receptors. J Neurosci 18:2423-2436.

Anggono V, Huganir RL (2012) Regulation of AMPA receptor trafficking and synaptic plasticity. Curr Opin Neurobiol 22(3):461-469.

Boudreau AC, Wolf ME (2005) Behavioral sensitization to cocaine is associated with increased AMPA receptor surface expression in the nucleus accumbens. J Neurosci 25:9144-9151.

Brebner K, Wong TP, Liu L, Liu Y, Campsall P, Gray S, Phelps L, Phillips AG, Wang YT (2005) Nucleus accumbens long-term depression and the expression of behavioral sensitization. Science 310:1340-1343.

Bredt DS, Nicoll RA (2003) AMPA receptor trafficking at excitatory synapses. Neuron 40:361-379.

Chowdhury S, Shepherd JD, Okuno H, Lyford G, Petralia RS, Plath N, Kuhl D, Huganir RL, Worley PF (2006) Arc/Arg3.1 interacts with the endocytic machinery to regulate AMPA receptor trafficking. Neuron 52:445-459.
Fukazawa Y, Saitoh Y, Ozawa F, Ohta Y, Mizuno K, Inokuchi K (2003) Hippocampal LTP is accompanied by enhanced F-actin content within the dendritic spine that is essential for late LTP maintenance in vivo. Neuron 38:447-460.

Guzowski JF, Lyford GL, Stevenson GD, Houston FP, McGaugh JL, Worley PF, Barnes CA (2000) Inhibition of Activity-Dependent Arc protein expression in the rat hippocampus impairs the maintenance of long-term potentiation and the consolidation of long-term memory. J Neurosci 20:3993-4001.

Halpain S (2000) Actin and the agile spine: how and why do dendritic spines dance? Trends Neurosci 23:141-146.

Hou YY, Lu B, Li M, Liu Y, Chen J, Chi ZQ, Liu JG (2009) Involvement of actin rearrangements within the amygdala and the dorsal hippocampus in aversive memories of drug withdrawal in acute morphine-dependent rats. J Neurosci 29:12244-12254.

Huang F, Chotiner JK, Steward O (2007) Actin polymerization and ERK phosphorylation are required for Arc/Arg3.1 mRNA targeting to activated synaptic sites on dendrites. J Neurosci 27:9054-9067.

Husi H, Ward MA, Choudhary JS, Blackstock WP, Grant SG (2000) Proteomic analysis of NMDA receptor-adhesion protein signaling complexes. Nat Neurosci 3:661-669.

Hutcheson DM, Everitt BJ, Robbins TW, Dickinson A (2001) The role of withdrawal in heroin addiction: enhances reward or promotes avoidance? Nat Neurosci 4:943-947.

Isaac JT, Ashby MC, McBain CJ (2007) The role of the GluR2 subunit in AMPA receptor function and synaptic plasticity. Neuron 54:859-871.

Kaech S, Parmar H, Roelandse M, Bornmann C, Matus A (2001) Cytoskeletal microdifferentiation: a mechanism for organizing morphological plasticity in dendrites. Proc Natl Acad Sci U S A 98:7086-7092.

Kalivas PW (2009) The glutamate homeostasis hypothesis of addiction. Nat Rev Neurosci 10:561-572.

Kalivas PW, Volkow N, Seamans J (2005) Unmanageable motivation in addiction: a pathology in prefrontal-accumbens glutamate transmission. Neuron 45:647-650

Kawasaki Y, Jin C, Suemaru K, Kawasaki H, Shibata K, Choshi T, Hibino S, Gomita Y, Araki H (2005) Effect of glutamate receptor antagonists on place aversion induced by naloxone in single-dose morphine-treated rats. Br J Pharmacol 145:751-757.

Kelleher RJ 3rd, Govindarajan A, Tonegawa S (2004) Translational regulatory mechanisms in persistent forms of synaptic plasticity. Neuron 44:59-73.

Kenny PJ (2007) Brain reward systems and compulsive drug use. Trends Pharmacol Sci 28:135-141.

Kim CH, Lisman JE (1999) A role of actin filament in synaptic transmission and long-term potentiation. J Neurosci 19:4314-4324.

LeDoux JE (2000) Emotion circuits in the brain. Annu Rev Neurosci 23:155-184.

Lee SH, Simonetta A, Sheng M (2004) Subunit rules governing the sorting of internalized AMPA receptors in hippocampal neurons. Neuron 43:221-236.

Li M, Hou YY, Lu B, Chen J, Chi ZQ, Liu JG (2009) Expression pattern of neural synaptic plasticity marker-Arc in different brain regions induced by conditioned drug withdrawal from acute morphine-dependent rats. Acta Pharmacol Sin 30:282-290.

Lyford GL, Yamagata K, Kaufmann WE, Barnes CA, Sanders LK, Copeland NG, Gilbert DJ, Jenkins NA, Lanahan AA, Worley PF (1995) Arc, a growth factor and activity-regulated gene, encodes a novel cytoskeletonassociated protein that is enriched in neuronal dendrites. Neuron 14:433-445.

Malinow R, Malenka RC (2002) AMPA receptor trafficking and synaptic plasticity. Annu Rev Neurosci 25:103-126.

Maren S (2005) Synaptic mechanisms of associative memory in the amygdala. Neuron 47:783-786

Marie-Claire C, Courtin C, Roques BP, Noble F (2004) Cytoskeletal genes regulation by chronic morphine treatment in rat striatum. Neuropsychopharmacology 29:2208-2215.

Matus A (2000) Actin-based plasticity in dendritic spines. Science 290:754-758.

Messaoudi E, Kanhema T, Soulé J, Tiron A, Dagyte G, da Silva B, Bramham CR (2007) Sustained Arc/Arg3.1 synthesis controls long-term potentiation consolidation through regulation of local actin polymerization in the dentate gyrus in vivo. J Neurosci 27:10445-10455. 
Mucha RF, van der Kooy D, O’Shaughnessy M, Bucenieks P (1982) Drug reinforcement studied by the use of place conditioning in rat. Brain Res 243:91-105.

Plath N, Ohana O, Dammermann B, Errington ML, Schmitz D, Gross C, Mao X, Engelsberg A, Mahlke C, Welzl H, Kobalz U, Stawrakakis A, Fernandez E, Waltereit R, Bick-Sander A, Therstappen E, Cooke SF, Blanquet V, Wurst W, Salmen B, et al. (2006) Arc/Arg3.1 is essential for the consolidation of synaptic plasticity and memories. Neuron 52:437-444.

Rex CS, Gavin CF, Rubio MD, Kramar EA, Chen LY, Jia Y, Huganir RL, Muzyczka N, Gall CM, Miller CA, Lynch G, Rumbaugh G (2010) Myosin IIb regulates actin dynamics during synaptic plasticity and memory formation. Neuron 67:603-617.

Rial Verde EM, Lee-Osbourne J, Worley PF, Malinow R, Cline HT (2006) Increased expression of the immediate-early gene arc/arg3.1 reduces AMPA receptor-mediated synaptic transmission. Neuron 52:461-474.

Rumpel S, LeDoux J, Zador A, Malinow R (2005) Postsynaptic receptor trafficking underlying a form of associative learning. Science 308:83-88.

Schafer DA (2002) Coupling actin dynamics and membrane dynamics during endocytosis. Curr Opin Cell Biol 14:76-81.

Shepherd JD, Rumbaugh G, Wu J, Chowdhury S, Plath N, Kuhl D, Huganir RL, Worley PF (2006) Arc/Arg3.1 mediates homeostatic synaptic scaling of AMPA receptors. Neuron 52:475-484.

Steward O, Worley PF (2001) Selective targeting of newly synthesized Arc mRNA to active synapses requires NMDA receptor activation. Neuron 30:227-240.

Steward O, Worley P (2002) Local synthesis of proteins at synaptic sites on dendrites: role in synaptic plasticity and memory consolidation? Neurobiol Learn Mem 78:508-527.

Thomas MJ, Beurrier C, Bonci A, Malenka RC (2001) Long-term depres- sion in the nucleus accumbens: a neural correlate of behavioral sensitization to cocaine. Nat Neurosci 4:1217-1223.

Toda S, Shen HW, Peters J, Cagle S, Kalivas PW (2006) Cocaine increases actin cycling: effects in the reinstatement model of drug seeking. J Neurosci 26:1579-1587.

Tsvetkov E, Carlezon WA, Benes FM, Kandel ER, Bolshakov VY (2002) Fear conditioning occludes LTP-induced presynaptic enhancement of synaptic transmission in the cortical pathway to the lateral amygdala. Neuron 34:289-300.

Van den Oever MC, Goriounova NA, Li KW, Van der Schors RC, Binnekade R, Schoffelmeer AN, Mansvelder HD, Smit AB, Spijker S, De Vries TJ (2008) Prefrontal cortex AMPA receptor plasticity is crucial for cueinduced relapse to heroin-seeking. Nat Neurosci 11:1053-1058.

Watanabe T, Nakagawa T, Yamamoto R, Maeda A, Minami M, Satoh M (2002) Involvement of glutamate receptors within the central nucleus of the amygdala in naloxone-precipitated morphine withdrawal-induced conditioned place aversion in rats. Jpn J Pharmacol 88:399-406.

Wenthold RJ, Petralia RS, Blahos J II, Niedzielski AS (1996) Evidence for multiple AMPA receptor complexes in hippocampal CA1/CA2 neurons. J Neurosci 16:1982-1989.

Whittaker VP, Gray EG (1962) The synapse: biology and morphology. Br Med Bull 18:223-228.

Wikler A, Pescor FT (1967) Classical conditioning of a morphine abstinence phenomenon, reinforcement of opioid-drinking behavior and 'relapse' in morphine-addicted rats. Psychopharmacologia 10:255-284.

Yarar D, Waterman-Storer CM, Schmid SL (2005) A dynamic actin cytoskeleton functions at multiple stages of clathrin-mediated endocytosis. Mol Biol Cell 16:964-975.

Yu SY, Wu DC, Liu L, Ge Y, Wang YT (2008) Role of AMPA receptor trafficking in NMDA receptor-dependent synaptic plasticity in the rat lateral amygdala. J Neurochem 106:889-899. 